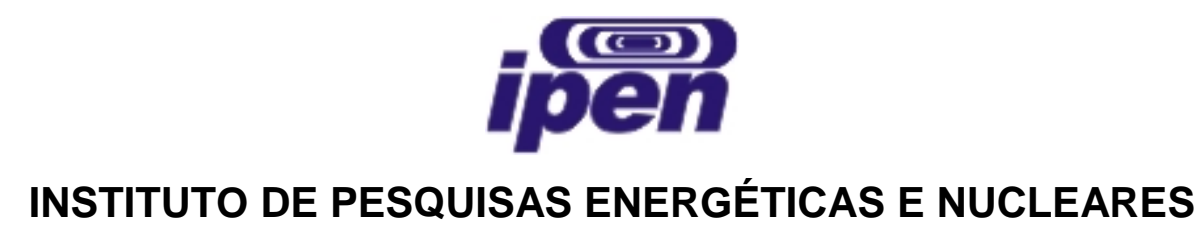

Autarquia associada à Universidade de São Paulo

IMPLEMENTAÇÃO DA IRRADIAÇÃO DE CORPO INTEIRO EM RADIOTERAPIA

ÂNGELA BEATRIZ HABITZREUTER

Tese apresentada como parte dos requisitos para obtenção do Grau de Mestre em Ciências na Área de Tecnologia Nuclear - Aplicações.

Orientadora:

Dra. Laura Natal Rodrigues

SÃO PAULO

2010 
Dedico este trabalho

Ao meu querido e amado César, por estar sempre ao meu lado.

Aos meus pais, Inês e Rudi pelo incentivo aos estudos e por terem sido uma base tão sólida. 


\section{AGRADECIMENTOS}

À Dra. Laura Natal Rodrigues, minha orientadora, pela oportunidade, por acreditar na minha capacidade de trabalho, e por me mostrar sempre o melhor caminho, principalmente nos momentos de dúvida.

Aos físicos do departamento de radioterapia do Hospital das Clínicas de São Paulo, por terem permitido o uso dos aparelhos e materiais necessários para o desenvolvimento do trabalho.

Às físicas Gabriela, Camila e Laura Furnari por terem auxiliado nas medidas e pelas valiosas discussões.

Aos queridos colegas de aprimoramento, Cristian, Bruno, Guilherme, Caroline e Milton, que sempre me auxiliaram no que era necessário.

Aos professores do IPEN que sempre estiveram a disposição para qualquer dúvida que ocorresse.

À equipe de engenharia do Hospital das Clínicas de São Paulo, que auxiliaram na confecção dos suportes necessários para realização de algumas medidas. 


\title{
IMPLEMENTAÇÃO DA IRRADIAÇÃO DE CORPO INTEIRO EM RADIOTERAPIA
}

\author{
Ângela Beatriz Habitzreuter
}

\section{RESUMO}

Ao implementar uma técnica de tratamento, as características do feixe nas condições de irradiação precisam ser bem conhecidas e estudadas. Cada um dos parâmetros utilizados para cálculo de dose deve ser medido e validado antes da utilização dos mesmos na rotina clínica. Isso se torna ainda mais necessário quando se tratam de técnicas especiais.

Neste trabalho estão descritos todos os parâmetros e medidas necessárias para a implementação da irradiação de corpo inteiro numa instalação projetada para tratamentos convencionais, e que faz uso de geometrias não convencionais para gerar os tamanhos de campos alargados. Além disso, são apresentados os dados de comissionamento desta modalidade no Hospital das Clínicas de São Paulo utilizando a comparação de três tipos de detectores para medidas de dose de entrada durante tratamentos de irradiação de corpo inteiro. 
IMPLEMENTATION OF TOTAL BODY IRRADIATION IN RADIOTHERAPY

\author{
Ângela Beatriz Habitzreuter
}

\begin{abstract}
Before implementing a treatment technique, the characteristics of the beam under irradiation conditions must be well acknowledged and studied. Each one of the parameters used to calculate the dose has to be measured and validated before its utilization in clinical practice. This is particularly necessary when dealing with special techniques.

In this work, all necessary parameters and measurements are described for the total body irradiation implementation in facilities designed for conventional treatments that make use of unconventional geometries to generate desired enlarged field sizes. Furthermore, this work presents commissioning data of this modality at Hospital das Clínicas of São Paulo using comparison of three detectors types for measurements of entrance dose during total body irradiation treatment.
\end{abstract}




\section{SUMÁRIO}

Página

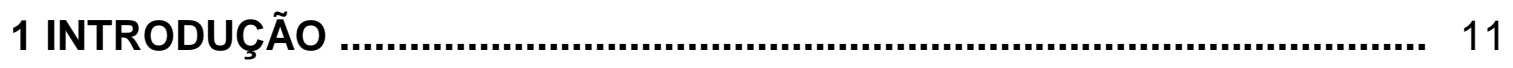

1.1 Considerações Gerais ................................................................... 11

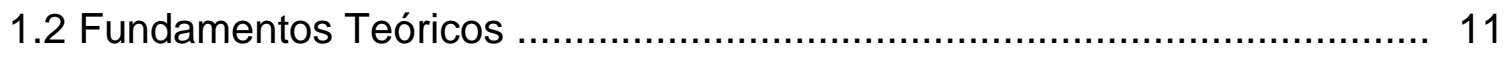

1.2.1 Irradiação de Corpo Inteiro (TBI) ................................................. 11

1.2.2 Comissionamento para procedimentos de TBI .................................. 12

1.2.3 Dosimetria In-vivo ........................................................................ 13

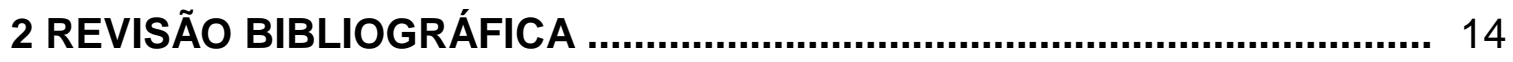

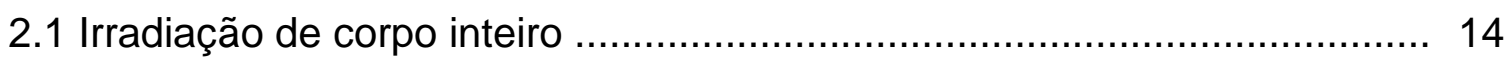

2.1.1 Métodos de irradiação .................................................................. 14

2.1.2 Métodos de compensação para variação de contorno ........................... 17

2.2 Dosimetria termoluminescente ...................................................... 17

2.2.1 Dosímetros termoluminescentes ................................................... 20

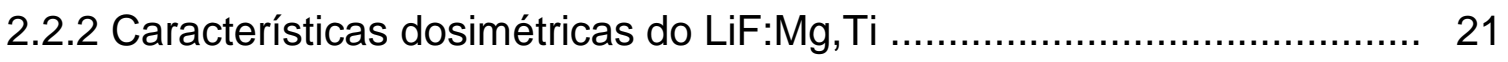

2.2.2.1 Curva de Emissão .................................................................. 21

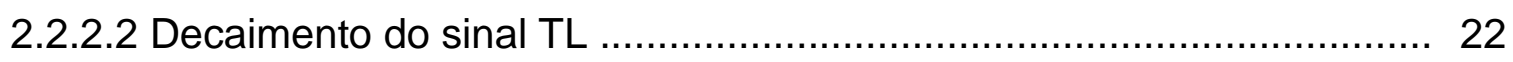

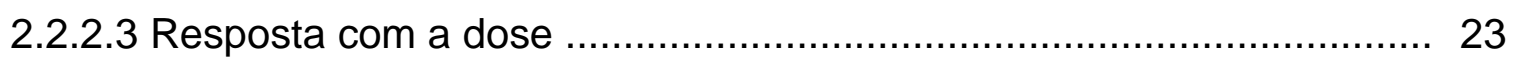

2.2.2.4 Resposta com a Taxa de Dose ................................................. 24

2.2.2.5 Dependência energética ........................................................... 24

2.2.2.6 Tratamento térmico .................................................................. 24

2.3 Sistema de dosimetria MOSFET ................................................. 25

2.4 Parâmetros de dose em radioterapia ................................................... 27

2.4.1 Distribuição de dose na profundidade ............................................... 27

2.4.2 Percentual de Dose Profunda .......................................................... 28

2.4.2.1 Dependência com a profundidade e qualidade do feixe ..................... 29

2.4.2.2 Região de aumento da dose (build-up) ............................................ 29

2.4.2.3 O efeito do tamanho e forma do campo ......................................... 30

2.4.2.4 Dependência com a distância da fonte até a superfície ...................... 30

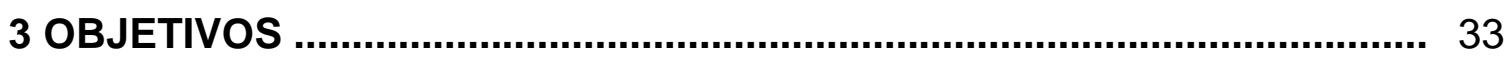

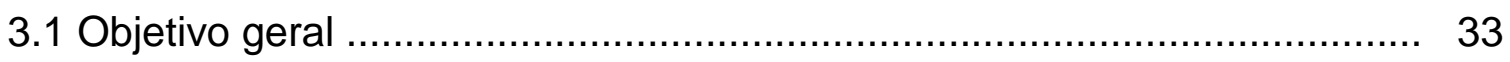

3.2 Objetivos específicos ………….................................................... 33 
4.1 Comissionamento do acelerador linear para implementação de TBI ......... 34

4.1.1 Obtenção dos dados de Percentual de Dose Profunda ......................... 35

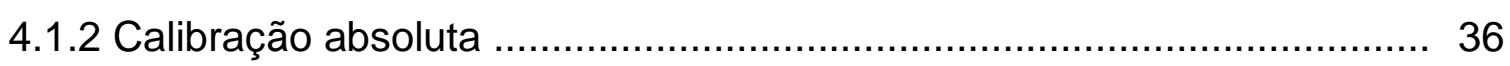

4.1.3 Transmissão da bandeja e CSR dos atenuadores .............................. 37

4.1.4 Determinação da dose fora do raio central (OAR) ................................ 38

4.2 Calibração dos instrumentos para medidas in vivo ................................. 39

4.2.1 Dosímetros termoluminescentes LiF:Mg,Ti ...................................... 40

4.2.1.1 Seleção dos TLDs .......................................................... 40

4.2.1.2 Calibração dos dosímetros termoluminescentes LiF:Mg,Ti ................ 42

4.2.2 Calibração dos dosímetros microMOSFETs ...................................... 42

4.3 Simulação de tratamento ................................................................... 43

5 RESULTADOS E DISCUSSÃO …......................................................... 45

5.1 Comissionamento do acelerador linear para implementação de TBI ......... 45

5.1.1 Obtenção dos dados de Percentual de Dose Profunda ........................ 45

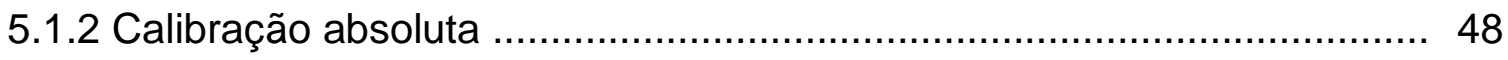

5.1.3 Transmissão da bandeja e CSR dos atenuadores .............................. 48

5.1.4 Determinação da dose fora do raio central (OAR) ............................... 49

5.2 Calibração dos instrumentos para medidas in vivo .................................. 51

5.2.1 Dosímetros termoluminescentes LiF:Mg,Ti ...................................... 51

5.2.1.1 Seleção dos TLDs ............................................................ 51

5.2.1.2 Calibração dos dosímetros termoluminescentes LiF:Mg,Ti ................ 53

5.2.2 Calibração dos dosímetros microMOSFETs ....................................... 53

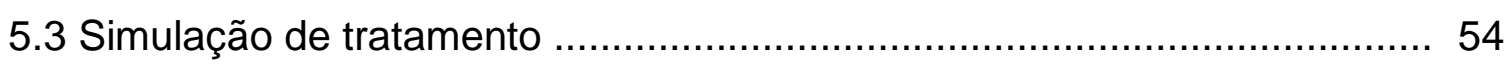

6 CONCLUSÕES …............................................................................ 56

REFERÊNCIAS BIBLIOGRÁFICAS .................................................. 57 


\section{LISTA DE TABELAS}

Página

TABELA 1- Propriedades do TLD-100 (Metcalfe et al., 1997)

TABELA 2- Características do pico de emissão do LiF:Mg,Ti (Metcalfe et al., 1997)

TABELA 3- Tratamentos térmicos mais utilizados nos principais dosímetros TL (Da Rosa, 2000)

TABELA 4- Leituras obtidas a partir da irradiação da câmara de ionização com diferentes taxas de dose

TABELA 5- Valores de PDP medidos com e sem a placa de acrílico 47

TABELA 6- CSR do $\mathrm{Pb}$ nas condições de TBI 48

TABELA 7- CSR do cerrobend nas condições de TBI

TABELA 8- OAR obtidos a partir da variação da distância em relação ao raio central para profundidade de $10 \mathrm{~cm}$

TABELA 9- OAR obtidos a partir da variação da distância em relação ao raio central para profundidade de $5 \mathrm{~cm}$

TABELA 10- Valores obtidos a partir dos procedimentos de seleção dos dosímetros termoluminescentes

TABELA 11- Fatores de calibração obtidos a partir da irradiação dos dosímetros mMOSFET

TABELA 12- Valores utilizados para simulação do tratamento

TABELA 13- Medidas de dose de entrada do campo AP para diferentes detectores

TABELA 14- Medidas de dose de entrada do campo PA para diferentes detectores 


\section{LISTA DE FIGURAS}

Página

FIGURA 1- A razão do pico de dose para a dose na linha média no raio central versus a espessura do paciente (AAPM, 1986)

FIGURA 2- Modelo de bandas de energia para um cristal ideal (a) e um cristal real (b) (Mackinlay, 1981)

FIGURA 3- Modelo de bandas de energia para a termoluminescência (Mackinlay, 1981)

FIGURA 4- Desenho esquemático da curva de decaimento do LiF:Mg,Ti (Metcalfe et al., 1997)

FIGURA 5- Variação da resposta de dose do LiF: Mg,Ti (Metcalfe et al., 1997)

FIGURA 6- Diagrama esquemático de um detector MOSFET (Metcalfe et al., 1997)

FIGURA 7- PDP é $\left(D_{d} / D_{d_{0}}\right) \times 100$, onde $d$ é uma profundidade qualquer e $d_{0}$ é a profundidade de dose máxima (Khan, 1984)

FIGURA 8- Distribuição de dose na profundidade no eixo central para diferentes qualidades de feixes de fótons (Khan, 1984)

FIGURA 9- Mudanças no percentual de dose profunda com a variação da SSD (Khan, 1984)

FIGURA 10- Planta da sala utilizada para irradiação de corpo inteiro no HCFMUSP 34

FIGURA 11- Esquema de irradiação utilizado para TBI 35

FIGURA 12- Posicionamento das placas de $\mathrm{Pb}$ para medida de CSR

FIGURA 13- Posicionamento das placas de cerrobend para medida de CSR FIGURA 14- Esquema de irradiação para obtenção da dose fora do raio central

FIGURA 15- Esquema de posicionamento dos dosímetros termoluminescentes para seleção dos mesmos

FIGURA 16- Leitora de TLDs Harshaw modelo 3500

FIGURA 17- Esquema de irradiação para calibração dos dosímetros mMOSFETs 
FIGURA 18- Posicionamento do objeto simulador Alderson Rando para simulação do tratamento

FIGURA 19- Posicionamento dos detectores durante a simulação do tratamento

FIGURA 20- Percentual de Dose Profunda para as condições de TBI (sem a placa de acrílico)

FIGURA 21- Percentual de Dose Profunda para as condições de TBI (com a placa de acrílico) 46

FIGURA 22- Comparação das curvas de Percentual de Dose Profunda nas condições de TBI (com e sem a placa de acrílico) 47

FIGURA 23- Fatores de correção para dose fora do raio central 51 


\section{LISTA DE ABREVIATURAS E SIGLAS}

$\begin{array}{ll}\text { AAPM } & \text { American Association of Physicist in Medicine } \\ \text { AP } & \text { Antero Posterior } \\ \text { CI } & \text { Câmara de ionização } \\ \text { CSR } & \text { Camada Semi Redutora } \\ \text { DAP } & \text { Diâmetro Antero Posterior } \\ \sigma & \text { Desvio padrão } \\ \text { IMRT } & \text { Intensity Modulated Radiation Therapy } \\ \text { LET } & \text { Linear Energy Transference } \\ \mu & \text { Coeficiente de atenuação linear } \\ \text { MOSFET } & \text { Metal Oxide Semiconductor Field Effect Transistor } \\ \text { OAR } & \text { Off Axis Ratio } \\ \text { PA } & \text { Postero Anterior } \\ \text { PDP } & \text { Percentual de Dose Profunda } \\ \text { SSD } & \text { Source Surface Distance } \\ \text { TAR } & \text { Tissue-Air Ratios } \\ \text { TBI } & \text { Total Body Irradiation } \\ \text { TL } & \text { Termoluminescente } \\ \text { TLD } & \text { Thermoluminescence Dosimetry } \\ \text { TMR } & \text { Tissue-Maximum Ratio } \\ \text { TPR } & \text { Tissue-Phantom Ratio } \\ \text { UM } & \text { Unidade Monitora }\end{array}$




\section{INTRODUÇÃo}

\subsection{Considerações Gerais}

Os primeiros dados sobre irradiação de corpo inteiro vieram com base em observações feitas nos sobreviventes das bombas atômicas de Hiroshima e Nagasaki (Metcalfe et al., 1997), tendo sido observado que as pessoas expostas apresentaram uma série de sintomas relacionados a alterações dos componentes sanguíneos. Anos mais tarde iniciavam-se tentativas de utilização da Irradiação de Corpo Inteiro (TBI) como forma de preparo para transplante de medula óssea. McFarland, em 1961, foi o primeiro a identificar que o condicionamento prétransplante de medula óssea era importante para a recuperação da nova medula e nos casos de leucemia, para a erradicação do tumor (Mercês, 2009).

Apesar de ser uma técnica antiga, seu uso vem crescendo nos últimos anos o que pode ser explicado em função do grande número de transplantes realizados a cada ano, além dos bons resultados obtidos com a união de TBI e quimioterapia. No Brasil, de 2003 a 2009, houve uma ampliação do número de transplantes de medula óssea em $57,51 \%$, incluindo as três modalidades: autólogos (células retiradas do próprio paciente), aparentados (células retiradas de pessoas da mesma família) e não-aparentados (células doadas por voluntários), sendo que a irradiação de corpo inteiro é realizada nas duas últimas (INCA, 2010).

O objetivo deste trabalho consiste na descrição dos pontos relevantes para a implementação da técnica em centros onde são utilizadas instalações projetadas para tratamentos de radioterapia convencional, porém modificadas para procedimentos com campos alargados.

\subsection{Fundamentos Teóricos}

\subsubsection{Irradiação de Corpo Inteiro (TBI)}

A Irradiação de Corpo Inteiro empregando feixes de fótons de megavoltagem é normalmente usada como parte do regime de condicionamento para transplante de medula óssea, o qual é usado para tratamento de várias doenças tais como leucemia, anemia aplásica, linfoma, mieloma múltiplo, doenças auto-imunes, falhas congênitas do metabolismo (Khan, 1984). A função do TBI é 
destruir as células tumorais e a medula óssea dos receptores e imunosuprimir os pacientes suficientemente para evitar rejeição da medula óssea transplantada. Normalmente os pacientes submetem-se a um esquema de quimioterapia antes do TBI e do transplante. Embora possa ser usada somente a quimioterapia como preparação ao transplante, a adição do TBI é considerado benéfica. O TBI tem ação no corpo inteiro incluindo as áreas santuário onde a quimioterapia pode não ser efetiva. Além disso, partes selecionadas do corpo tais como pulmão, rins, e cabeça podem ser protegidas se necessário (Khan, 1984).

\subsubsection{Comissionamento para procedimentos de TBI}

Uma vez selecionadas a máquina e a técnica de tratamento de TBI, deve ser realizado um comissionamento completo para a técnica proposta. Os parâmetros dosimétricos para TBI são os mesmos que aqueles para radioterapia padrão incluindo calibração absoluta do feixe, Percentual de Dose Profunda (PDP) e perfis do feixe (off-axis ratios - OARs) (Podgorsak, 2005). Porém, esses parâmetros devem ser medidos nas condições específicas de TBI para obter dados confiáveis para uso em TBI clínico.

Vários problemas dosimétricos específicos de dosimetria de campos alargados precisam ser considerados no comissionamento. Estes problemas estão relacionados aos objetos simuladores e câmaras de ionização que são usados nas medidas dos parâmetros dosimétricos. Em comparação com a radioterapia padrão, em TBI os objetos simuladores são geralmente menores que o tamanho de campo usado e menores que o paciente. Isso causa diferenças nas condições de espalhamento que parece afetar o rendimento do feixe bem como as PDPs indispensáveis para a determinação do tempo de tratamento ou unidades monitoras (UMs) necessárias para alcançar a dose prescrita no tumor.

A exatidão dos dados dosimétricos de TBI podem ser afetados pela porção relativamente grande de cabo irradiado da câmara de ionização em virtude dos grandes campos usados na técnica, como também por características de fuga de corrente e saturação da câmara, os quais tornam-se mais acentuados nas taxas de dose relativamente baixas usadas em TBI (Podgorsak, 2005). 


\subsubsection{Dosimetria In-vivo}

Os problemas inerentes aos métodos de cálculo tornam muito difíceis a determinação exata da distribuição da dose para TBI. Além disso, variações na posição do paciente podem alterar drasticamente a distribuição. Por essa razão é desejável ter disponível uma técnica de medida in-vivo. Um método conveniente para encontrar as doses na linha média utiliza dosímetros termoluminescentes (TLD) na entrada e na saída do paciente.

A determinação exata da dose de entrada na pele geralmente é difícil, visto que nessa situação há uma condição de falta de equilíbrio eletrônico. Isso pode ser resolvido utilizando-se uma espessura de material tecido equivalente sobre o TLD para gerar a condição de equilíbrio eletrônico. Desta forma é possível estimar a dose num ponto próximo a superfície de entrada do feixe, na profundidade de dose máxima (dose de entrada) e outro ponto de estimativa de dose pode ser na superfície de saída do feixe (dose de saída). 


\section{REVISÃO BIBLIOGRÁFICA}

\subsection{Irradiação de corpo inteiro}

\subsubsection{Métodos de irradiação}

Antes de instituir procedimentos de radioterapia com campos alargados, devem ser tomadas decisões médicas sobre a dose total a ser entregue ao paciente, a taxa de dose, a uniformidade desejada, a duração do tratamento, o número total de frações e o tempo total do tratamento. Algumas vezes, alguns desses parâmetros podem ser comprometidos por causa das limitações dos equipamentos de terapia disponíveis.

Muitas das primeiras experiências clínicas de procedimentos de TBI foram instaladas em centros com estruturas especialmente projetadas para irradiações de campos alargados. Com o uso crescente destes campos grandes, muitos pacientes estão sendo tratados hoje com unidades de tratamento convencionais, tais como os aceleradores lineares adaptados para esse tipo de procedimento. Os métodos atuais de irradiação de campos grandes podem então, de um modo geral ser divididos em três categorias:

a) Instalações dedicadas, especialmente construídas para tratamentos com campos grandes;

b) Instalações projetadas para tratamentos de radioterapia convencional, porém modificadas para procedimentos com campos grandes;

c) Instalações projetadas para tratamentos convencionais, nas quais se faz necessário uso de geometrias não convencionais para gerar os tamanhos de campos desejados.

Porém, existem alguns parâmetros físicos que devem ser considerados e otimizados para cada instituição. Os mais comuns são energia da radiação, distância de tratamento, a escolha de tratamentos ântero-posterior (AP), laterais ou uma combinação deles, e taxa de dose. A FIG. 1 mostra a razão do pico de dose para a dose na linha média no raio central como uma função da espessura do paciente para campos de radiação paralelos e opostos. Os dados foram representados por meio de gráfico para três energias, Cobalto-60, feixes de fótons de 6 e $15 \mathrm{MV}$, e tamanhos de campos de $50 \times 50 \mathrm{~cm}^{2}$ em várias distâncias de 
tratamento. A região horizontal sombreada indica uma uniformidade de dose dentro de $15 \%$. Para tratamentos AP, os diâmetros dos pacientes adultos geralmente variam na faixa entre 18 e $26 \mathrm{~cm}$. A região A representa esses diâmetros dos pacientes e a uniformidade de dose de $15 \%$. Os efeitos de falta de homogeneidade dos tecidos e dose de build-up próximo a superfície não foram considerados. Somente um aparelho de Cobalto-60 com uma SSD (Source Surface Distance) de $80 \mathrm{~cm}$ fica fora dessa região de uniformidade de dose para diâmetros de pacientes maiores que $25 \mathrm{~cm}$. Assim sendo, para a maioria das técnicas de campos grandes, os tratamentos AP irão gerar uma uniformidade maior que $15 \%$ até para radiação de Cobalto- 60 . Os procedimentos com feixes laterais e opostos podem ser representados pela região sombreada $B$, onde diâmetros laterais dos pacientes são presumidos alcançar entre 38 e $50 \mathrm{~cm}$. Somente os feixes de fótons com uma energia de 25 MV numa distância de 300 $\mathrm{cm}$ irão gerar uma uniformidade de dose dentro de $15 \%$ para um paciente com diâmetro de $50 \mathrm{~cm}$. Energias mais baixas e distâncias menores de tratamento irão resultar em variações maiores de dose. Desta forma, verifica-se que o uso de um feixe de Cobalto-60 com feixes laterais e opostos tenderá a produzir variações de dose muito grandes. Várias conclusões podem ser extraídas desses dados:

1) Para energias mais altas, menores são as variações de dose (excluindo os efeitos de região de build-up e heterogeneidade dos tecidos);

2) Para distâncias de tratamento maiores, menores são as variações de dose;

3) Para pacientes com diâmetros maiores, maiores são as variações de dose;

4) Tratamentos AP/PA irão gerar uma variação de dose de no máximo $15 \%$ para a maioria das distâncias e energias de megavoltagem;

5) Campos laterais e opostos dão normalmente uma variação de dose maior se comparados com tratamentos AP/PA, principalmente para adultos. Em casos pediátricos ou feixes de raios $\mathrm{x}$ de energia mais alta, talvez possa ser alcançada uma uniformidade de dose de $15 \%$ com campos laterais. 


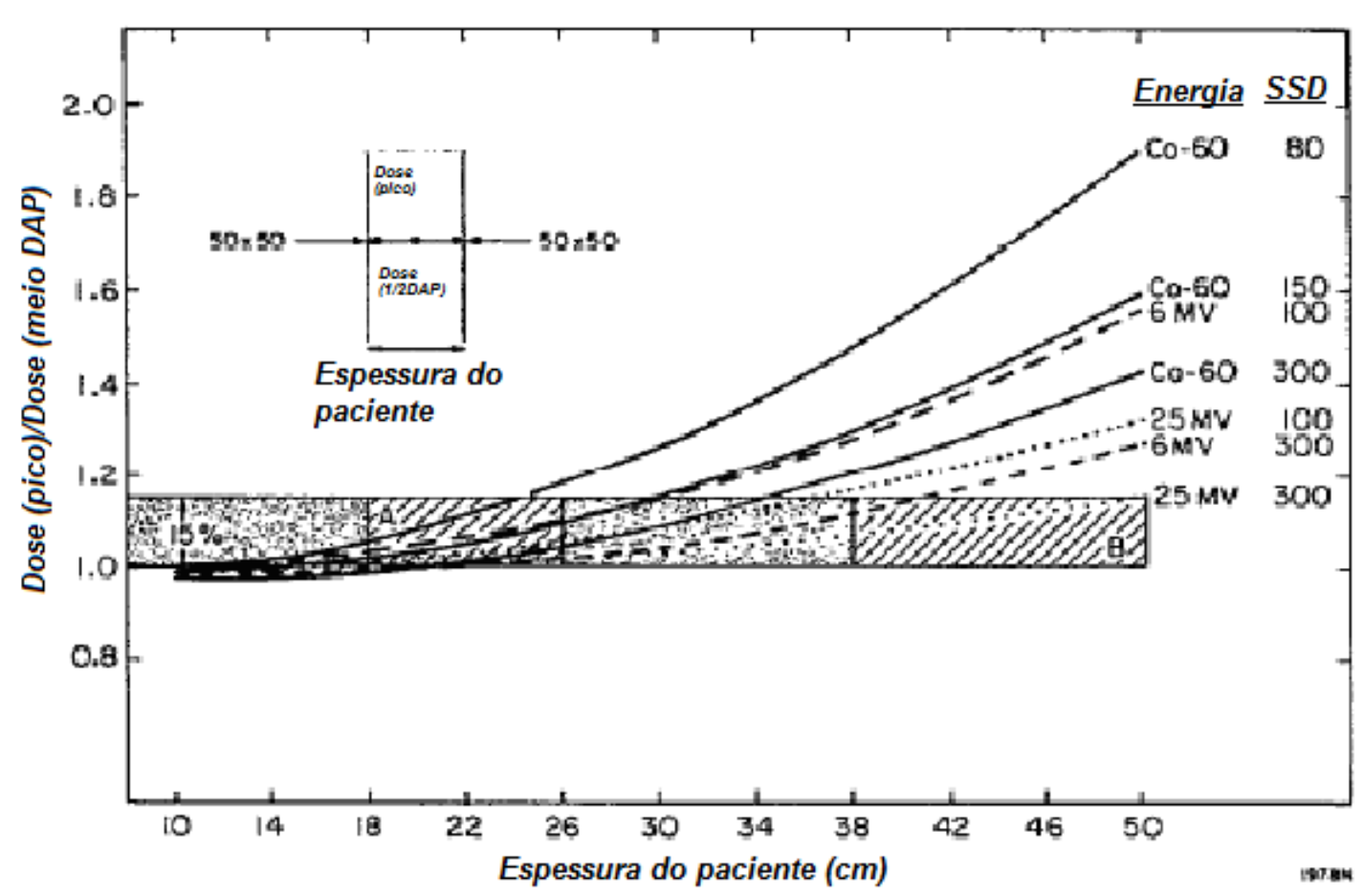

FIGURA 1- A razão do pico de dose para a dose na linha média no raio central versus a espessura do paciente. A região horizontal sombreada indica uma variação de $15 \%$ nessa razão. A região sombreada $A$ representa o intervalo típico de diâmetros de pacientes adultos no sentido $A P$, ao passo que a região $B$ representa 0 intervalo de diâmetros de pacientes adultos na direção lateral (AAPM, 1986).

Quando feixes de fótons de alta energia provenientes de um acelerador linear forem usados, algumas considerações devem ser feitas em relação ao efeito da dose baixa na região de build-up. Atualmente não há dados sobre problemas clínicos deste efeito, mas a dose na região de build-up pode ser aumentada adicionando um modificador do feixe tal como um plástico próximo a região da superfície da pele. A escolha do material, sua espessura e localização irão depender do critério de dose recomendado pelos especialistas clínicos.

Alguns protocolos clínicos requerem baixas taxas de dose de tratamento, entre 5 a $10 \mathrm{cGy} / \mathrm{min}$ (AAPM, 1986). Normalmente em aceleradores lineares as condições do feixe podem ser ajustadas para reduzir a corrente do feixe ou a freqüência de repetição do pulso. Se forem desejadas taxas de dose convencionais, as mesmas podem ser ajustadas levando em conta os efeitos de diminuição (inverso do quadrado da distância) devido às distâncias grandes de 
tratamento. Em todos estes casos, medidas dosimétricas devem ser realizadas sob as condições de operação para assegurar a entrega correta de dose (AAPM, 1986).

\subsubsection{Métodos de compensação para variação de contorno}

Um dos aspectos mais desafiadores do TBI é criar uma geometria de tratamento que proporcione uma uniformidade de dose em toda linha média do corpo. As irregularidades do corpo geram uma diferença de dose inaceitável as quais causam irradiação excessiva das áreas menos espessas como pescoço, cabeça e pernas. Existem dois métodos principais de compensação para a variação de contorno, que são: bolus tecido-equivalente e compensadores por falta de tecido (AAPM, 1986).

O primeiro método é o uso de bolus equivalente a tecido, colocado diretamente na pele para compensar a curvatura do corpo. O principal problema desse método são as altas doses na pele.

Outra forma de compensação para a variação de contorno é a colocação de materiais atenuadores nos locais de menor espessura de tecido. $O$ método envolve comparação das PDPs para as diferentes partes do corpo, além de levar em conta as diferenças nas distâncias de cada ponto. A espessura dos atenuadores pode ser calculada usando:

$$
I=I_{0} e^{-\mu x}
$$

onde $\mu$ é o coeficiente de atenuação linear e $x$ é a espessura necessária de material atenuador.

Esse método também é utilizado para calcular a espessura de material atenuador necessária para diminuir a dose no pulmão, já que a dose máxima aceitável para esse órgão é geralmente menor do que a dose de prescrição para a irradiação de corpo inteiro (AAPM, 1986).

\subsection{Dosimetria termoluminescente}

O tamanho pequeno dos materiais termoluminescentes (TLD) tem sido explorada nos estudos clínicos inserindo-os nos locais apropriados do corpo humano antes de expor o paciente à radiação ionizante durante o diagnóstico ou terapia (Metcalfe et al., 1997). Os TLDs expostos podem então ser retirados e 
analisados. Dessa forma os radioterapeutas são capazes de determinar doses efetivamente entregues para órgãos críticos internos durante esse procedimento e, por meio dessa informação, podem prescrever outros tratamentos necessários. Tal vantagem dificilmente será possível com qualquer outro tipo de dosímetro.

Os materiais utilizados para dosimetria termoluminescente, quando aquecidos e após serem expostos a radiação ionizante, podem emitir luz e por isso são ditos termoluminescentes. A quantidade de luz emitida, proporcional a quantidade de radiação recebida é mensurável e o processo de quantificação da dose de radiação é denominado dosimetria termoluminescente.

Os TLDs são constituídos de cristais e o fenômeno da termoluminescência pode ser explicado qualitativamente por meio de um modelo de bandas de energia (Mackinlay, 1981). No interior de um cristal ideal existem três bandas distintas de energia (FIG. 2(a)). Uma banda de energia menor, denominada de banda de valência, onde os elétrons permanecem em estados ligados de energia. Uma banda de energia maior, denominada de banda de condução, representativa de todos os elétrons em estados não ligados de energia e, portanto, livres para migrarem através da rede cristalina. E uma banda intermediária, conhecida como a banda proibida. No caso de um cristal ideal não condutor, à temperatura ambiente, a banda de valência se encontra repleta de elétrons e a banda de condução vazia. É altamente improvável para um elétron da banda de valência atravessar a banda proibida rumo a banda de condução, a menos que esteja sob a influência de forças externas.

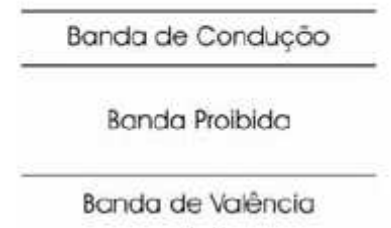

(a)

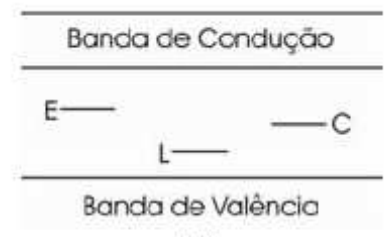

(b)

FIGURA 2- Modelo de bandas de energia para um cristal ideal (a) e um cristal real (b) (Mackinlay, 1981).

No caso de um cristal real, existem imperfeições/defeitos na banda proibida que permitem aprisionar os elétrons da banda de condução, como 
ilustrado na FIG 2(b). A presença dos defeitos em um material é importante para o fenômeno da termoluminescência.

Na FIG. 2(b), o nível de energia $E$ (região com excesso de carga positiva) representa uma armadilha de elétrons, C (região com excesso de carga negativa) representa uma armadilha de buraco e $L$ é um centro de luminescência, onde os elétrons e os buracos podem se recombinar emitindo fótons. O processo da termoluminescência observado em um material exposto à radiação ionizante pode ser dividido em dois estágios (Mackinlay, 1981): (i) ionização e aprisionamento do elétron, e (ii) recombinação de um elétron com um buraco com emissão de fótons. A FIG. 3 ilustra a configuração da banda de energia para cada estágio.

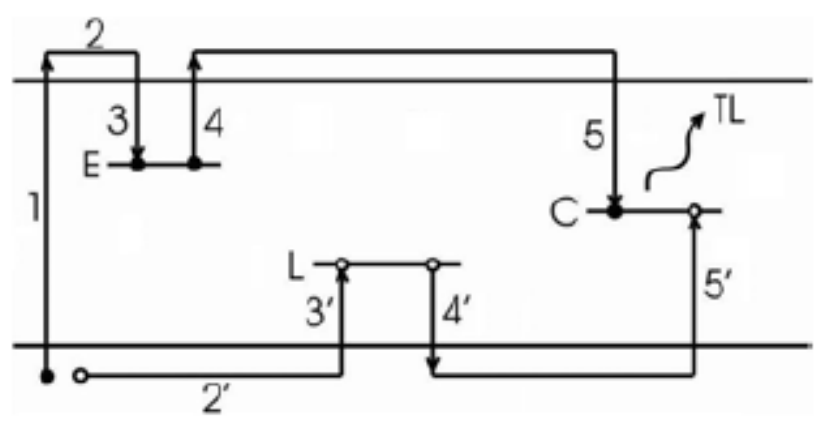

FIGURA 3- Modelo de bandas de energia para a termoluminescência (Mackinlay, 1981).

O material termoluminescente (TL) absorve a radiação ionizante e, como efeito da interação da radiação com a matéria, são produzidos pares elétron-buraco. Em termos do modelo de bandas, essa situação é equivalente a transferência de elétrons da banda de valência para a banda de condução (passo 1). Esses elétrons encontram-se agora em estados não ligados de energia, podendo então se mover livremente no material (passo 2). Uma vez que as armadilhas de elétrons $\mathrm{E}$ estejam presentes, os elétrons podem ser aprisionados (passo 3). Os buracos positivos criados se comportam de maneira semelhante. Eles podem migrar pela banda de valência (passo 2') e podem ser aprisionados pelas armadilhas de buracos C (passo 3').

Muitos dos centros de buracos apresentam instabilidade térmica e podem decair rapidamente à temperatura ambiente (passo 4'). Já que os elétrons aprisionados permanecerão nessa condição até que recebam energia suficiente 
para escapar de suas armadilhas, a probabilidade disso ocorrer depende da profundidade da armadilha e da temperatura do material. $O$ elétron pode adquirir energia térmica suficiente e ser libertado (passo 4). Os elétrons libertados, ao retornarem para o estado de menor energia na banda de valência, podem se combinar com os buracos nos centros de luminescência $L$, e o excesso de energia é liberado como fótons com comprimento de onda visível ou ultravioleta (passo 5). A quantidade de luz emitida depende da temperatura do material e do número de elétrons aprisionados e, portanto, da dose absorvida no cristal (Mackinlay, 1981).

\subsubsection{Dosímetros termoluminescentes}

O requisito principal para um material dosimétrico ser usado dessa forma é a equivalência de tecido. Alta sensibilidade é necessária para que o tamanho do TLD possa ser tão pequeno quanto possível para medidas in vivo. Além disso, já que as doses usadas podem ser bastante altas é propriamente vantajoso que a resposta com a dose seja linear em um amplo intervalo de dose (McKeever, 1995).

Os materiais mais utilizados em dosimetria pessoal são LiF:Mg,Ti, o LiF:Mg, $\mathrm{Cu}, \mathrm{P}$ e $\mathrm{O} \mathrm{Al}_{2} \mathrm{O}_{3}$, por possuírem número atômico efetivo próximo ao do tecido, e o $\mathrm{CaF}_{2}$ e o $\mathrm{CaSO}_{4}: \mathrm{Dy}$, por sua alta sensibilidade (Campos, 1998). Quando esses fósforos são expostos a radiação ionizante, acumulam dentro de si a energia transferida da radiação por períodos relativamente longos, dependendo do material. Aconselha-se a utilização de materiais cujo armazenamento seja estável à temperatura ambiente.

Após uma irradiação, o cristal pode retornar à sua condição inicial, sendo para tanto necessário submetê-lo a um recozimento adequado que libere todos os elétrons armadilhados. Isso significa que os materiais TL são reutilizáveis.

A curva de emissão é a melhor característica de um fósforo termoluminescente e consiste em geral de vários picos. Ela representa a luz emitida pelo cristal em função da temperatura ou do tempo de aquecimento. Cada um desses picos está associado a uma determinada armadilha e é caracterizada pela temperatura em que ocorre o máximo de emissão. A formação de um pico de emissão TL está relacionada com a probabilidade de escape de elétrons da 
armadilha correspondente, isto é, quando a temperatura do fósforo é menor que a do pico considerado, poucos elétrons são liberados, e a luz emitida é fraca. Aquecendo-se o cristal, a probabilidade de escape aumenta, causando um aumento na emissão, que é máxima na temperatura do pico. A intensidade decresce em seguida devido à redução do número de elétrons armadilhados.

Em geral, a TL emitida por um fósforo aumenta com a exposição à radiação $X$ ou gama, atingindo um valor de saturação para exposições elevadas. Em algumas amostras esta resposta é linear, em outras, observa-se um crescimento mais rápido que o linear em alguns intervalos de exposição. A este último comportamento dá-se o nome de supralinearidade (Campos, 1998).

Um dos materiais termoluminescentes mais utilizados para dosimetria na radioterapia é o fluoreto de lítio dopado com magnésio e titânio ( $\mathrm{LiF}: \mathrm{Mg}, \mathrm{Ti})$, também conhecido como TLD-100. As propriedades desse material encontram-se na TAB. 1.

TABELA 1- Propriedades do TLD-100 (Metcalfe et al., 1997)

\begin{tabular}{lc}
\hline \multicolumn{1}{c}{ Propriedades } & $\mathrm{LiF}$ \\
\hline Material de dopagem & $\mathrm{Mg}, \mathrm{Li}$ \\
Número atômico efetivo (tecido 7,64$)$ & 8,2 \\
Densidade física $\left(\mathrm{g} \cdot \mathrm{cm}^{-3}\right)$ & 2,64 \\
Máximo comprimento de onda da luz emitida $(\mathrm{nm})$ & 400 \\
Decaimento do sinal TL do pico principal a $20^{\circ} \mathrm{C}$ & $<10 \%$ por ano \\
Supralinearidade (Gy) & 1 \\
\hline
\end{tabular}

\subsubsection{Características dosimétricas do LiF:Mg, $\mathrm{Ti}$}

\subsubsection{Curva de Emissão}

A curva de emissão termoluminescente representa a variação da intensidade do sinal TL em função da temperatura de aquecimento durante a leitura ou do tempo de aquisição. A FIG. 4 mostra a curva de emissão do LiF:Mg,Ti. Até a temperatura de $250^{\circ} \mathrm{C}$ podem ser obs ervados seis diferentes picos de emissão. Eles são associados a diferentes armadilhas. 
Os picos que geralmente são utilizados para avaliação da dose no LiF:Mg,Ti são os picos IV e V (Metcalfe et al., 1997).

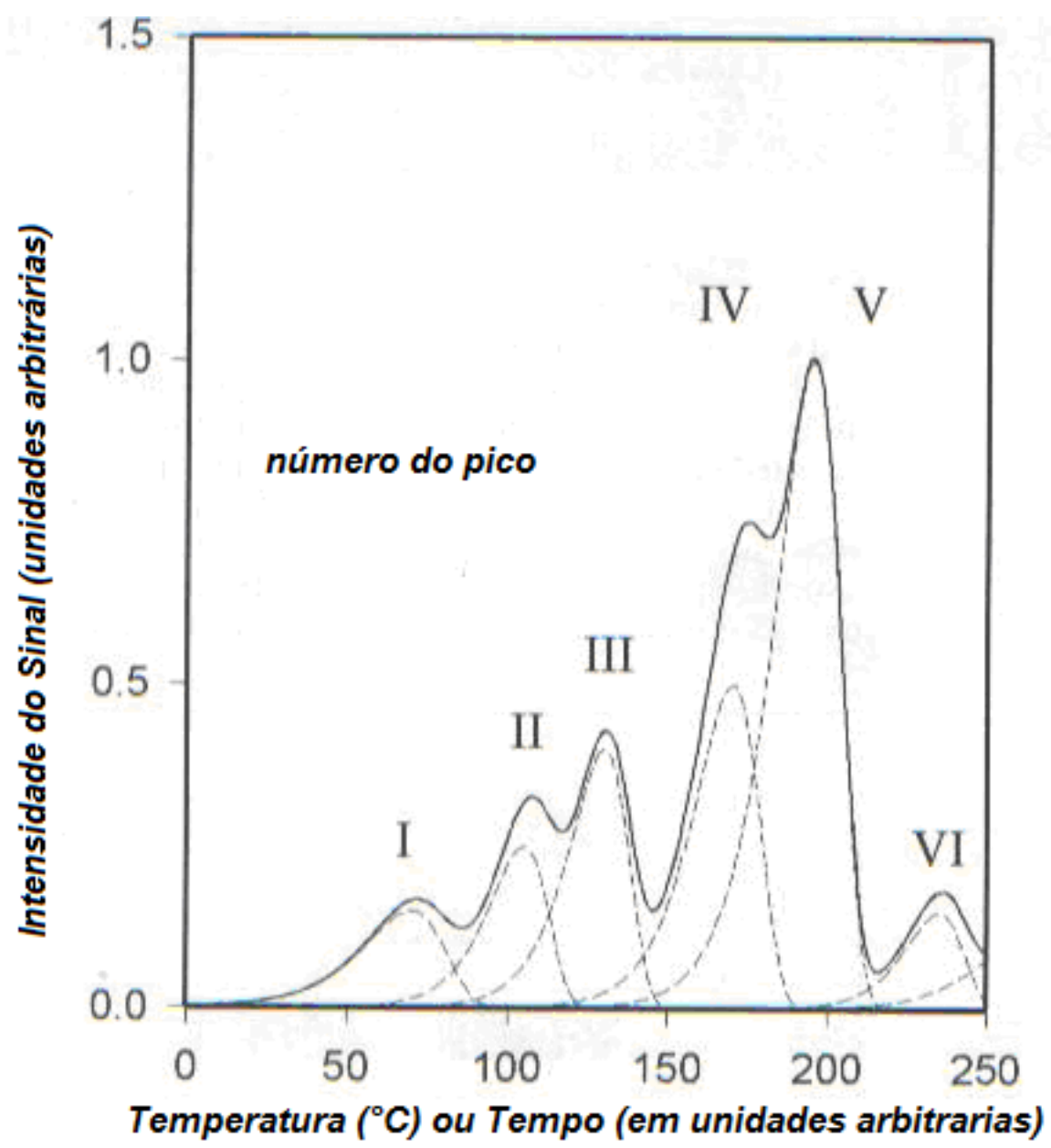

FIGURA 4- Desenho esquemático da curva de decaimento do LiF:Mg, Ti (Metcalfe et al., 1997).

\subsubsection{Decaimento do sinal TL}

Até com intervalos de energia relativamente amplos entre a banda de condução e as armadilhas, há uma probabilidade que um elétron ganhe energia suficiente para escapar da armadilha. Quanto menor a diferença de energia maior a probabilidade de emissão espontânea de luz o qual reduz a população das armadilhas e então reduz o sinal TL. Esse processo é chamado decaimento (Metcalfe et al., 1997). As meias vidas para diferentes armadilhas no LiF:Mg,Ti a temperatura ambiente é de poucos minutos a vários anos. Esses valores estão listados na TAB. 2. 
TABELA 2- Características do pico de emissão do LiF:Mg,Ti (Metcalfe et al., 1997).

\begin{tabular}{ccccc}
\hline Pico & $\begin{array}{c}\text { Intervalos } \\
\text { de energia } \\
\text { aproximadas }\end{array}$ & $\begin{array}{c}\text { Temperaturas } \\
\text { de Leitura } \\
\left({ }^{\circ} \mathrm{C}\right)\end{array}$ & $\begin{array}{c}\text { Contribuição } \\
\text { aproximada para } \\
\text { leitura }\end{array}$ & $\begin{array}{c}\text { Meia-vida para } \\
\text { temperatura } \\
\text { ambiente }\end{array}$ \\
\hline I & 1,04 & 70 & 0 & 10 min \\
II & 1,07 & 105 & 0,2 & 20 horas \\
III & 1,05 & 130 & 0,3 & 6 meses \\
IV & 1,53 & 170 & 0,5 & 10 anos \\
V & 2,21 & 195 & 1 & 80 anos \\
VI & 1,70 & 235 & 0,1 & $>100$ anos \\
\hline
\end{tabular}

Os picos IV e V, que são os picos que geralmente são usados em dosimetria não exibem um decaimento considerável. O decaimento do LiF:Mg,Ti é de $5 \%$ em 12 semanas (Metcalfe et al., 1997).

\subsubsection{Resposta com a dose}

A FIG. 5 mostra a resposta com a dose de um dosímetro TL típico para radiação de baixo LET (Linear Energy Transference) tal como fótons e elétrons. Quatro intervalos podem ser diferenciados. Entre o ponto A e B os níveis de leitura de dose para doses muito pequenas. Entre os pontos $B$ e $C$ a resposta é linear com a dose absorvida. Este é o intervalo mais útil para medidas. Nos níveis de dose acima de $\mathrm{C}$ as leituras superestimam as doses, uma vez que a sensibilidade dos dosímetros é aumentada. Esse fenômeno é chamado supralinearidade, e precisa ser considerado para muitas aplicações em radioterapia. Em doses de radiações muito mais altas, a sensibilidade relativa diminui novamente em razão do dano da radiação ao detector (Metcalfe et al., 1997). 


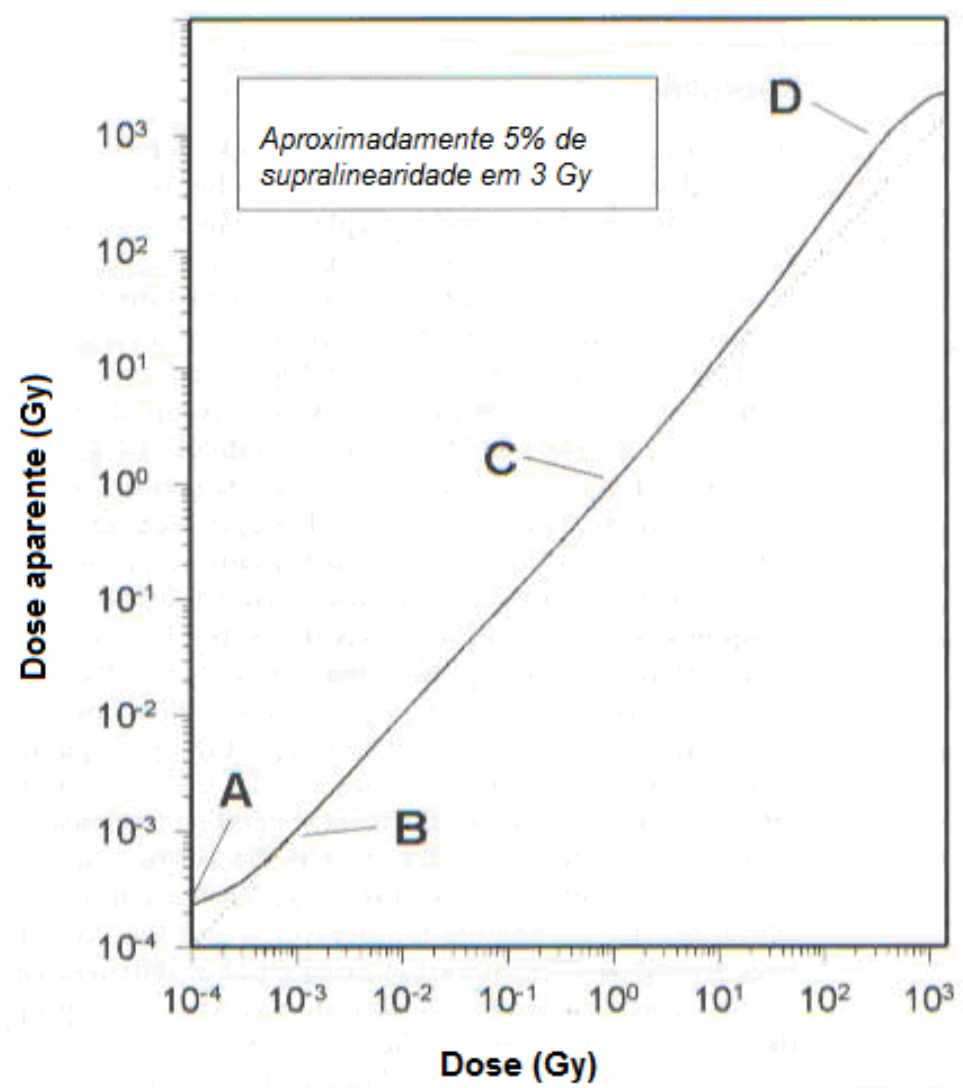

FIGURA 5- Variação da resposta de dose do LiF: Mg,Ti (Metcalfe et al., 1997).

\subsubsection{Resposta com a Taxa de Dose}

Nenhuma dependência com a taxa de dose foi observada para LiF:Mg,Ti até taxas de dose de $10^{8} \mathrm{~Gy} / \mathrm{s}$, o que parece ser igualmente valido para outros tipos de dosímetros TL (Metcalfe et al., 1997).

\subsubsection{Dependência energética}

O número atômico efetivo de 8,2 , comparado com o tecido $(7,4)$ torna o LiF:Mg,Ti um material quase tecido equivalente. Essa propriedade é refletida na resposta energética de fótons fazendo com que a resposta do material TL seja pouco dependente da energia da radiação incidente. Contudo, para se obter uma dosimetria mais exata, é necessário corrigir a resposta $T L$ do detector devido à sua dependência energética (Metcalfe et al., 1997).

\subsubsection{Tratamento térmico}

Quando se deseja utilizar um dosímetro termoluminescente repetidas vezes é importante saber qual o melhor tratamento térmico a ser usado com a 
finalidade de devolver-lhe as condições existentes antes da sua primeira exposição à radiação ionizante. Esse tratamento objetiva esvaziar completamente e estabilizar as armadilhas do material TL após a sua avaliação.

A estabilização térmica deve ser executada de modo muito acurado, devendo a sua duração e temperatura máxima ser bem reprodutíveis, uma vez que esses parâmetros afetam a sensibilidade dos denominados picos dosimétricos, aqueles localizados a temperaturas mais elevadas. Conseqüentemente, variações nesse procedimento térmico significarão uma variação na resposta do dosímetro, ou, em outras palavras, uma reprodutibilidade ruim desta resposta (Da Rosa, 2000).

$\mathrm{Na}$ TAB. 3 são apresentados os tratamentos térmicos mais recomendados para os principais materiais termoluminescentes.

TABELA 3- Tratamentos térmicos mais utilizados nos principais dosímetros TL (Da Rosa, 2000)

\begin{tabular}{cc}
\hline Material TL & Tratamento Térmico Pré \\
\hline $\mathrm{LiF}^{\mathrm{Mg}, \mathrm{Ti}}$ & $400^{\circ} \mathrm{C} / 1$ hora $+100^{\circ} \mathrm{C} / 2$ horas \\
$\mathrm{CaF}_{2}:$ Dy & $400^{\circ} \mathrm{C} / 1$ hora $+100^{\circ} \mathrm{C} / 2$ horas \\
$\mathrm{CaSO}_{4}: \mathrm{Dy}$ & $300^{\circ} \mathrm{C} / 3$ horas \\
$\mathrm{CaF}_{2}: \mathrm{Mn}$ & $400^{\circ} \mathrm{C} / 1$ hora \\
$\mathrm{LiF}: \mathrm{Mg}, \mathrm{P}, \mathrm{Cu}$ & $240{ }^{\circ} \mathrm{C} / 10$ minutos \\
\hline
\end{tabular}

\subsection{Sistema de dosimetria MOSFET}

Um novo desenvolvimento para a dosimetria das radiações ionizantes é o Metal Oxide Semiconductor Field Effect Transistor (MOSFET). Ele foi disponibilizado para dosimetria no início de 1980 e tem como característica a informação de dose integrada permitindo uma leitura imediata. A FIG. 6 mostra um diagrama esquemático de um detector MOSFET (Metcalfe et al., 1997). 


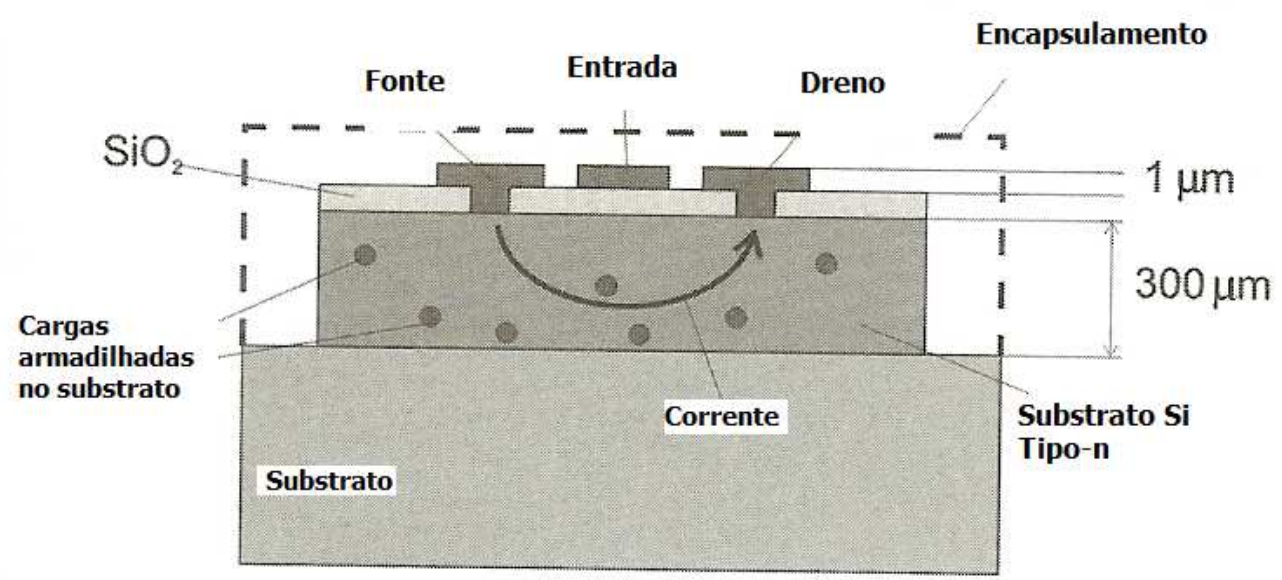

FIGURA 6- Diagrama esquemático de um detector MOSFET (Metcalfe et al., 1997)

A medida é baseada no fato de que a radiação ionizante altera o limiar de tensão na entrada. Essa variação de tensão normalmente é avaliada mantendo-se a corrente constante entre a fonte e o dreno e medindo a tensão de entrada. A alteração do limiar de tensão é proporcional a radiação absorvida. Mudanças na tensão, necessárias para manter a corrente constante, são geradas por causa dos portadores de carga (elétrons ou buracos) que são gerados na camada isolante de óxido de silício e são permanentemente armadilhados. Cargas positivas (buracos) se movem em direção a interface $\mathrm{Si}-\mathrm{SiO}_{2}$ e são presos levando a um crescimento da carga do $\mathrm{SiO}_{2}$ na entrada do MOSFET. Esses detectores podem ser usados no modo ativo ou passivo. No modo ativo, a entrada é carregada positivamente em relação a fonte durante a irradiação. $O$ campo elétrico no óxido de entrada reduz a recombinação de pares elétron buraco (induzida por ionização) fazendo com que mais buracos sejam armadilhados na interface $\mathrm{Si}-\mathrm{SiO}_{2}$.

A mudança no limiar de tensão depende da tensão de entrada durante a irradiação e da espessura da camada de isolante $\mathrm{SiO}_{2}$. Para alcançar uma sensibilidade aceitável a espessura deve ser relativamente grande (a espessura típica é 0,5 a $1 \mu \mathrm{m}$ ) (Metcalfe et al., 1997).

O MOSFET pode ser fabricado com um pequeno volume sensível, sendo denominado de microMOSFET um transistor de silício em miniatura, possui excelente resolução espacial e oferece pouca atenuação do feixe em virtude do 
seu pequeno tamanho, o qual é particularmente útil para dosimetria in-vivo (Podgorsak, 2005).

A principal desvantagem desses detectores é que eles têm um tempo de vida limitado em razão da sua característica de saturação (Podgorsak, 2005).

O dosímetro microMOSFET possui uma resposta linear com a dose na faixa utilizada na prática clínica e apresenta uma pequena dependência energética sendo necessária sua calibração para cada energia. Para baixas taxas (80 e $160 \mathrm{UM} / \mathrm{min}$ ) existe uma maior reprodutibilidade das medidas, com erro $0,4 \%$, enquanto que para altas taxas (240 e $320 \mathrm{UM} / \mathrm{min}$ ) encontra-se um erro de 4,2\% (Resende et al., 2010).

Os MOSFETs tem sido utilizados nos últimos anos em várias aplicações na radioterapia tanto para medidas in-vivo quanto para medidas em objetos simuladores, incluindo verificações de dose de rotina, medidas em braquiterapia, TBI, Radioterapia de Intensidade Modulada (IMRT), radioterapia intra-operatória e radiocirurgia (Podgorsak, 2005).

\subsection{Parâmetros de dose em radioterapia}

\subsubsection{Distribuição de dose na profundidade}

Quando o feixe incide em um paciente (ou em um objeto simulador) a dose absorvida no mesmo varia com a profundidade. Essa variação depende de algumas condições de medida, tais como: energia do feixe, profundidade, tamanho do campo, distância da fonte e sistema de colimação do feixe. Então, o cálculo da dose no paciente envolve considerações em relação a esses parâmetros, de como eles afetam a distribuição de dose na profundidade. Um ponto essencial no sistema de cálculo de dose é estabelecer a variação da dose na profundidade ao longo do eixo central do feixe. Alguns parâmetros foram definidos para esse propósito, sendo os mais importantes Percentual de Dose Profunda (PDP), Razão Tecido Ar (Tissue-Air Ratios- (TAR)), Razão Tecido Fantoma (Tissue-Phantom Ratios - TPR), e Razão Tecido Máximo (TissueMaximum Ratios - TMR). Esses parâmetros são geralmente derivados de medidas feitas em objetos simuladores de água usando câmaras de ionização pequenas. Embora outros sistemas dosimétricos tais como dosímetros termoluminescentes, diodos e filmes sejam usados ocasionalmente, câmaras de 
ionização são preferidas por causa da sua maior precisão e menor dependência energética (Khan, 1984).

\subsubsection{Percentual de Dose Profunda}

Uma maneira de caracterizar a distribuição de dose no eixo central é normalizar a dose na profundidade em relação a dose numa profundidade de referência. $O$ parâmetro percentual de dose profunda pode ser definido como o quociente, expresso como um percentual, da dose absorvida em qualquer profundidade $d$ em relação a dose absorvida na profundidade de referência $d_{0}$, ao longo do eixo central do feixe (FIG. 7).

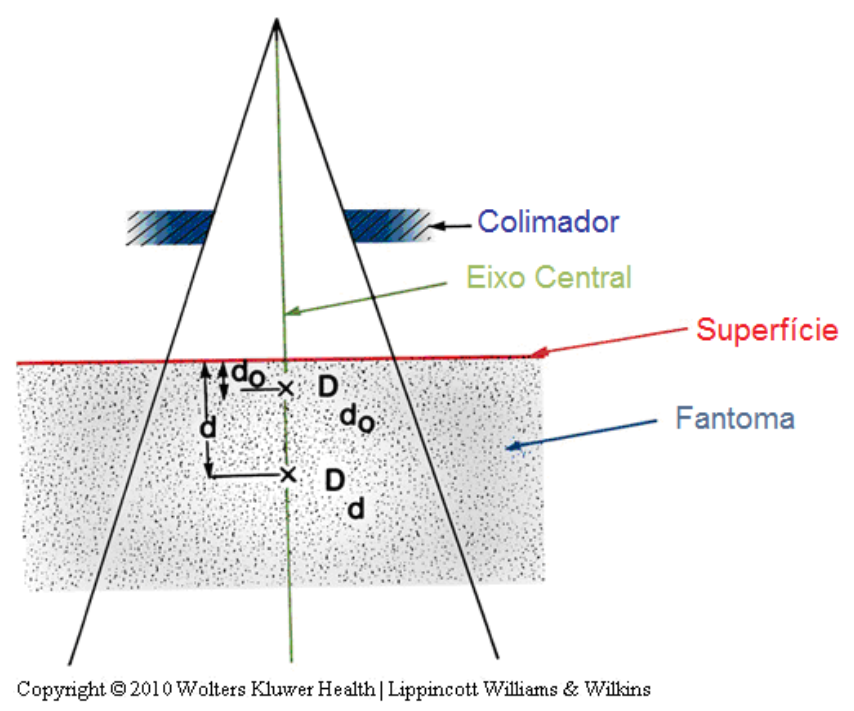

FIGURA 7- PDP é $\left(D_{d} / D_{d_{0}}\right) \times 100$, onde $d$ é uma profundidade qualquer e $d_{0}$ é a profundidade de dose máxima (Khan, 1984).

A PDP pode ser obtida por meio da seguinte expressão:

$$
P D P=\frac{D_{d}}{D_{d_{0}}} x 100
$$

Para ortovoltagem (até $400 \mathrm{KVp}$ ) e raios $\mathrm{X}$ de baixa energia, a profundidade de referência geralmente é na superfície $\left(d_{0}=0\right)$. Para maiores energias, a profundidade de referência é tomada como a posição do pico de dose absorvida $\left(d_{0}=d_{m}\right)$.

Na prática clínica, o valor máximo de dose absorvida no eixo central é denominado de dose máxima. 
Alguns parâmetros afetam a distribuição de dose no eixo central: isso inclui a energia ou qualidade do feixe, profundidade, tamanho ou forma do campo, distância da fonte a superfície e colimação do feixe (Khan, 1984).

\subsubsection{Dependência com a profundidade e qualidade do feixe}

O percentual de dose profunda (a partir da profundidade de dose máxima) aumenta com a energia do feixe. Feixes de maior energia tem um poder de penetração maior e então entregam um percentual mais alto de dose na profundidade (FIG. 8). Se os efeitos do inverso do quadrado da distância e espalhamento não são considerados, a variação do percentual de dose profunda é governada aproximadamente pela atenuação exponencial. Desta forma, a qualidade do feixe afeta o percentual de dose profunda por meio do coeficiente de atenuação médio $\bar{\mu}^{2}$. À medida que o $\bar{\mu}$ diminui, o feixe torna-se mais penetrante, resultando em um mais alto percentual de dose profunda em qualquer profundidade a partir da região de dose máxima.

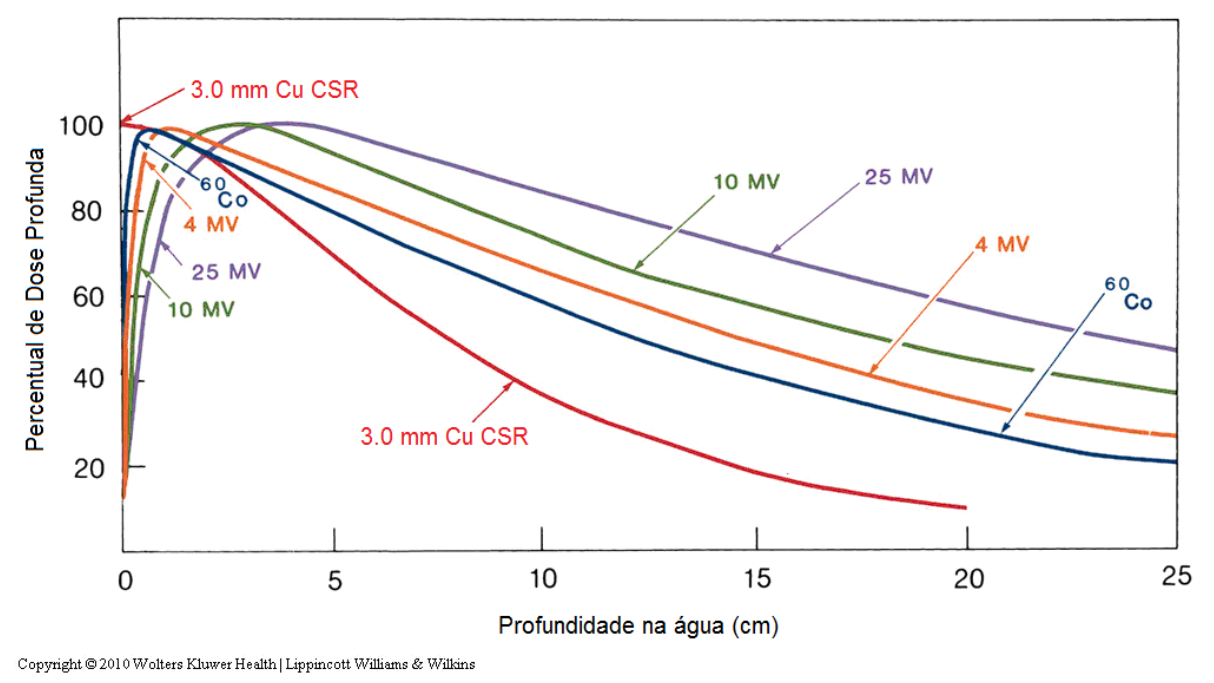

FIGURA 8- Distribuição de dose na profundidade no eixo central para diferentes qualidades de feixes de fótons (Khan, 1984).

\subsubsection{Região de aumento da dose (build-up)}

Como visto na FIG. 8, a PDP diminui com a profundidade a partir da profundidade de dose máxima. Porém, há um crescimento inicial da dose que torna-se maior a medida que a energia é aumentada. No caso de ortovoltagem ou raios $\mathrm{X}$ de baixa energia, a região de dose máxima é muito próxima a superfície. 
Mas, para feixes de mais alta energia, o ponto de dose máxima está mais profundo, dentro do tecido ou objeto simulador. A região entre a superfície e a dose máxima é chamada região de crescimento ou região de build-up.

\subsubsection{O efeito do tamanho e forma do campo}

Os tamanhos de campos podem ser especificados geometricamente ou dosimetricamente. O tamanho de campo geométrico corresponde ao campo definido pela luz de localização. O tamanho de campo dosimétrico ou físico é a distância interceptada por uma dada curva de isodose (geralmente a isodose de $50 \%$ ) em um plano perpendicular ao eixo do feixe a uma determinada distância da fonte (Khan, 1984).

Para um campo suficientemente pequeno, podemos assumir que a dose na profundidade em um ponto é efetivamente o resultado da radiação primária, isto é, os fótons que atravessaram o meio sem interagir. A contribuição dos fótons espalhados para a dose na profundidade é relativamente pequena ou praticamente zero. Mas à medida que o tamanho do campo é aumentado, a contribuição da radiação espalhada para dose absorvida aumenta. Pelo fato desse aumento na dose espalhada ser maior em profundidades maiores que nas profundidades de dose máxima, o percentual de dose profunda aumenta com o tamanho do campo.

O aumento no percentual de dose profunda causado pelo aumento no tamanho de campo depende da qualidade do feixe. Visto que a probabilidade de espalhamento ou a seção de choque diminui com o aumento da energia e os fótons de mais alta energia são espalhados mais predominantemente para frente, a dependência do percentual de dose profunda é menos evidente para feixes de alta energia que para feixes de baixa energia (Khan, 1984).

\subsubsection{Dependência com a distância da fonte até a superfície}

A fluência de fótons emitida por uma fonte de radiação pontual varia inversamente com o quadrado da distância da fonte. Embora a fonte clínica (fonte isotópica ou ponto focal) para feixes de terapia externos tenham um tamanho finito, a distancia da fonte a superfície é geralmente grande ( $\geq 80 \mathrm{~cm})$ de tal forma que a dimensão da fonte torna-se irrelevante em relação à variação da fluência de fótons com a distância. Desta forma, a taxa de exposição ou a taxa de dose de 
uma fonte varia inversamente com o quadrado da distância. A dependência da taxa de dose com o inverso do quadrado da distância assume a relação com 0 feixe primário, sem espalhamento. Em situações clínicas, porém, colimações e outros materiais espalhadores no feixe podem causar variações da lei do inverso do quadrado da distância.

Pelo fato do percentual de dose profunda determinar quanta dose pode ser entregue em uma profundidade em relação a profundidade de dose máxima, a SSD precisa ser tão grande quanto possível. Porém, pelo fato da taxa de dose diminuir com a distância, a SSD, na prática, é definida como a distância que gera um compromisso entre taxa de dose e percentual de dose profunda. Para o tratamento de lesões mais profundas com feixes de megavoltagem, a SSD mínima recomendada é $80 \mathrm{~cm}$.

Em uma dada situação clínica, porém, a SSD planejada para um paciente pode ser diferente da SSD padrão. Então, o percentual de dose profunda para uma SSD padrão precisa ser convertido para aquela SSD de tratamento aplicada. Embora existam métodos mais exatos, pode-se fazer essa correção através do fator de Mayneord, conforme Equação [3]. Esse método é baseado na aplicação da lei do inverso do quadrado da distância sem considerar mudanças no espalhamento (Khan, 1984)

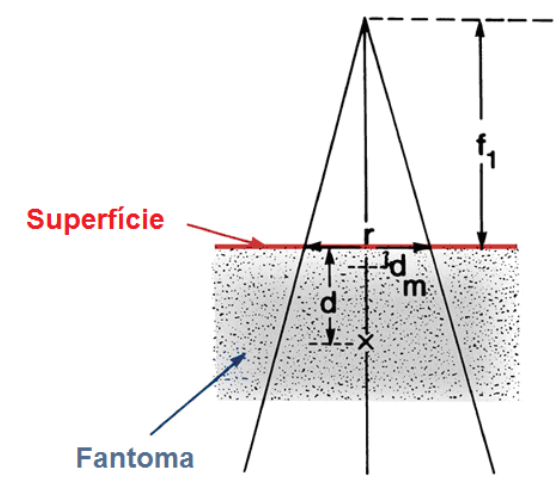

A

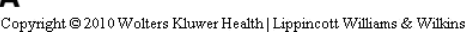

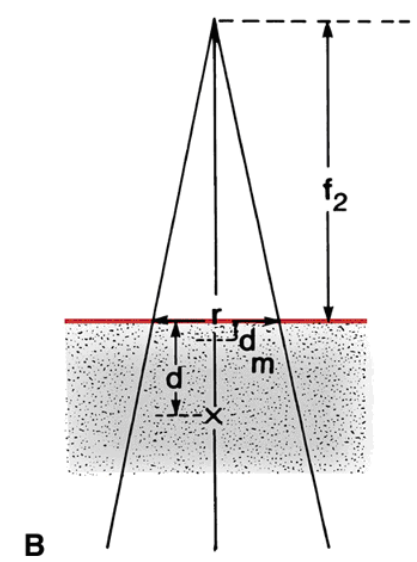

B

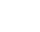

FIGURA 9- Mudanças no percentual de dose profunda com a variação da SSD. A condições de irradiação $(A)$ com $S S D=f 1$ e a condição $(B) \operatorname{com~SSD~=~f2.~Para~}$ ambas as condições, $r$ x $r$ é o tamanho de campo na superfície, e $d$ é a profundidade (Khan, 1984). 
A Equação [3] é usada então para determinar o fator de Mayneord:

$$
F=\left(\frac{f_{2}+d_{m}}{f_{1}+d_{m}}\right)^{2} \cdot\left(\frac{f_{1}+d}{f_{2}+d}\right)^{2}
$$

O fator de Mayneord funciona razoavelmente bem para campos pequenos já que o espalhamento é mínimo para essas condições. Porém o método pode gerar erros significativos sob condições extremas tais como energias baixas, campos grandes, grandes profundidades e grandes mudanças na SSD (Khan, 1984). 


\section{OBJETIVOS}

\subsection{Objetivo Geral}

Descrever os procedimentos de comissionamento para implementação de tratamentos com a técnica de TBI em uma sala de radioterapia adaptada.

\subsection{Objetivos específicos}

Avaliar as doses de entrada em tratamentos de TBI através de medidas com dosímetros termoluminescentes, microMOSFETs e câmara de ionização em um objeto simulador Alderson Rando.

Comparar diferentes dosímetros usados para verificação de dose em TBI. 


\section{MATERIAIS E MÉTODOS}

\subsection{Comissionamento do acelerador linear para implementação de TBI}

Algumas decisões precisam ser tomadas quando a implementação de TBI for feita numa instalação de radioterapia. As principais são posição de irradiação, sala de tratamento, energia do feixe, taxa de dose. No caso do Hospital das Clínicas da Faculdade de Medicina da Universidade de São Paulo (HCFMUSP), as escolhas foram pela técnica AP (FIG. 11), Aparelho Acelerador Linear 600C (Varian), energia de $6 \mathrm{MV}$ e taxa de dose de $80 \mathrm{UM} / \mathrm{min}$. Essas escolhas foram feitas principalmente pelo fato do aparelho escolhido estar na maior sala disponível, ou seja, sala onde havia possibilidade de obtenção do maior tamanho de campo.

As dimensões da sala utilizada encontram-se apresentadas na FIG. 10.

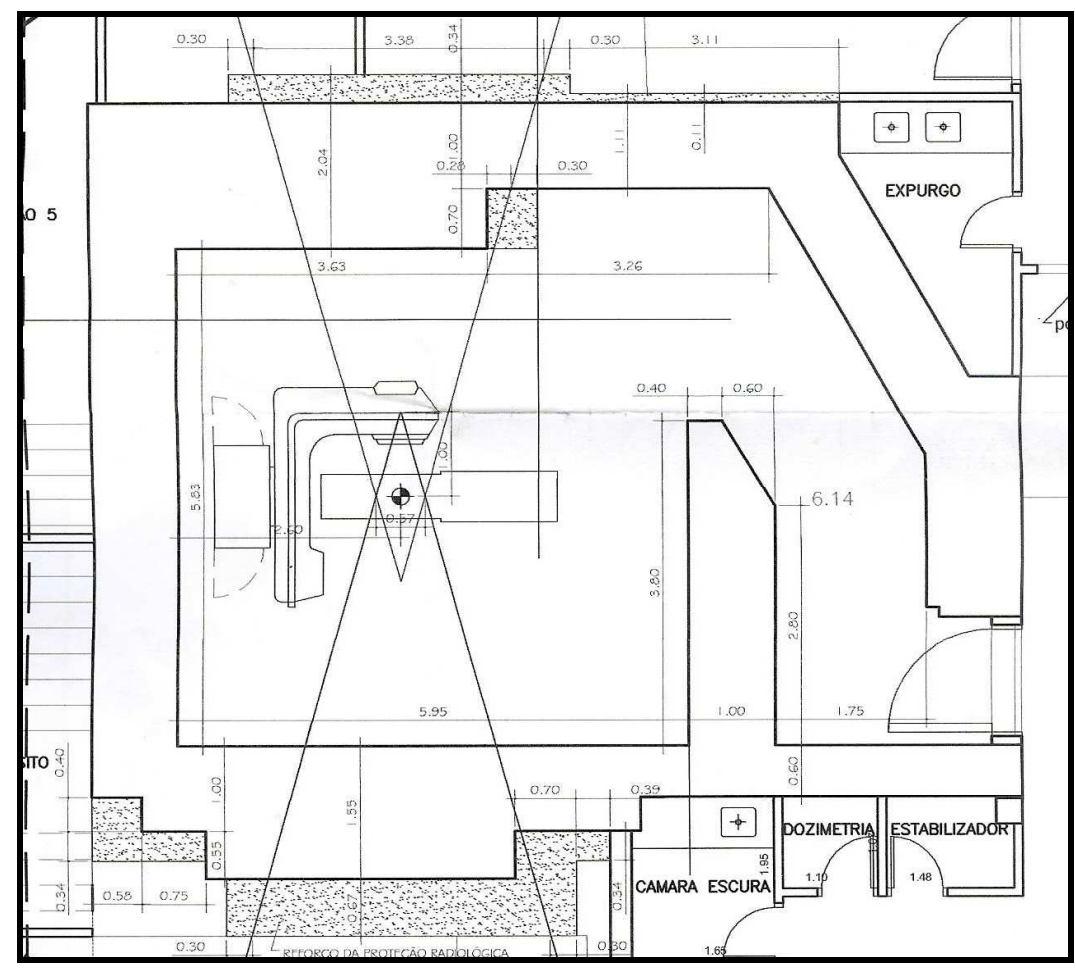

FIGURA 10- Dimensões da sala utilizada para irradiação de corpo inteiro no HCFMUSP.

Em função do feixe utilizado ser de alta energia, foi necessário adicionar um modificador do feixe (placa de acrílico) próximo a região da 
superfície da pele do paciente a fim de obtermos o ponto de máximo na pele ao invés dele acontecer na profundidade de $1,2 \mathrm{~cm}$.

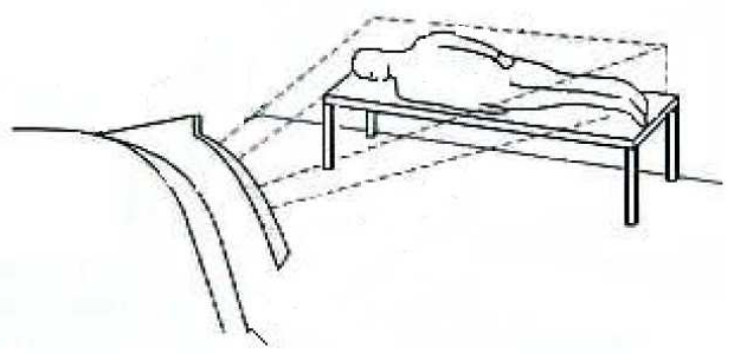

FIGURA 11- Esquema de irradiação utilizado para TBI

A dose utilizada para tratamento no protocolo HCFMUSP é 12 Gy, divididos em 6 frações durante 3 dias, sendo 2 aplicações diárias, com intervalo mínimo de 6 horas entre cada aplicação. A dose no pulmão é atenuada com 0 material cerrobend ${ }^{1}$ de tal forma que o mesmo receba no máximo 8 Gy.

Sendo assim, parâmetros dosimétricos tais como calibração absoluta, Percentual de Dose Profunda (PDP), medidas fora do eixo central (OAR) e medidas de transmissão foram obtidas.

\subsubsection{Obtenção dos dados de Percentual de Dose Profunda}

Para realização das medidas de PDP foram utilizados um objeto simulador de água Blue Phantom-IBA com dimensões $48 \times 48 \times 41 \mathrm{~cm}^{3}, 2$ objetos simuladores de água de 30×30×30 cm³ e câmara de ionização Scanditronix CC13 com volume de $0,13 \mathrm{~cm}^{3}$. Para a obtenção das medidas, o cabeçote do aparelho foi angulado $90^{\circ}$ de forma que a projeção do feixe f osse à horizontal (na parede), e o colimador angulado $45^{\circ}$ de forma a utilizar a di agonal do maior campo (40x40 $\mathrm{cm}^{2}$ ). A distância da fonte até a superfície do objeto simulador utilizada para as irradiações foi de $292,4 \mathrm{~cm}$ e a profundidade da câmara foi sendo alterada em uma faixa de $3 \mathrm{~cm}$ até $38,5 \mathrm{~cm}$, com um espaçamento de 0,5 cm. Para as medidas de dose na profundidade próximas da superfície foi utilizada a câmara de ionização de placas paralelas Markus (que é a câmara adequada para esse tipo de medida devido a sua alta resolução espacial), e a simulação das condições de tratamento foi feita com placas de água sólida $\left(30 \times 30 \times 1 \mathrm{~cm}^{3}\right)$, variando-se a

\footnotetext{
${ }^{1}$ Liga metálica de chumbo, bismuto, estanho e cádmio.
} 
profundidade da câmara da superfície até a $3 \mathrm{~cm}$, num intervalo de $2 \mathrm{~mm}$. Para cada irradiação foram utilizadas 100 unidades monitoras (UM) e taxa de dose de $320 \mathrm{UM} / \mathrm{min}$.

As medidas descritas acima foram realizadas com e sem a placa de acrílico usada para superficializar a dose.

\subsubsection{Calibração absoluta}

A calibração absoluta foi realizada com o mesmo esquema de irradiação da PDP. Para as irradiações foram utilizadas 100 UM, taxa de dose de $320 \mathrm{UM} / \mathrm{min}$ e distância da fonte até a superfície de $292,4 \mathrm{~cm}$. Para essa medida a câmara foi posicionada no raio central e na profundidade de $10 \mathrm{~cm}$ (profundidade de referência). Três medidas reprodutíveis foram assim obtidas.

Para utilizar as medidas da câmara de ionização para calibração absoluta é necessária a aplicação de fatores de correção e calibração. A dose absorvida na água, na profundidade de referência e qualidade do feixe $Q$ é dada por:

$$
D=M_{Q} * N_{D, W, Q_{0}} * K_{Q}
$$

em que $M_{Q}$ é a leitura do dosímetro com o ponto de referência da câmara posicionada na profundidade de referência e corrigido pelos fatores de influência como temperatura e pressão, calibração do eletrômetro e efeitos de polaridade e recombinação iônica. $N_{D, W, Q_{0}}$ é o fator de calibração em termos de dose absorvida na água para o dosímetro no feixe de qualidade $Q_{0}$, e $K_{Q, Q_{0}}$ é o fator específico da câmara o qual corrige a diferença entre a qualidade do feixe de referência $Q_{0}$ e a qualidade do feixe que está sendo usado $Q$ (IAEA, 2000).

O fator de calibração do conjunto dosimétrico é fornecido por um laboratório padrão secundário ou terciário, como por exemplo IPEN, que por sua vez possui rastreabilidade a um laboratório padrão primário. Essa calibração deve ser feita a cada dois anos.

O fator de correção para temperatura e pressão é obtido a partir da seguinte equação:

$$
F_{T, P}=\frac{273,2+T}{273,2+T_{0}} \frac{P_{0}}{P}
$$


onde T e P são temperatura e pressão no momento da medida e $T_{0}$ e $P_{0}$ são valores de referência $\left(20^{\circ} \mathrm{C}\right.$ e 101,3 KPa).

Para se obter o valor da dose absoluta com o instrumento de medida devidamente calibrado utiliza-se a equação abaixo:

$$
F_{c a l}=\left(\frac{D}{P D P(A, z, f, Q)}\right) / U M
$$

\subsubsection{Transmissão da bandeja e CSR dos atenuadores}

A determinação do coeficiente de atenuação linear $(\mu)$ do chumbo e do cerrobend (que são utilizados como atenuadores) foi feita a partir do valor da camada semi redutora, ou seja:

$$
C S R=\frac{\ln 2}{\mu}
$$

Para a determinação do coeficiente de atenuação linear do chumbo foi utilizado um tamanho de campo de $6 \times 6 \mathrm{~cm}^{2}$ e a câmara foi posicionada no ar (com capa de equilíbrio eletrônico para energia de $6 \mathrm{MV}$ ) na distância fonte superfície de $332 \mathrm{~cm}$. Os atenuadores de chumbo foram posicionados numa distância grande em relação ao paciente (DFS=65,4 cm), de acordo com a FIG. 12. A primeira medida foi feita somente com uma placa de acrílico antepondo o feixe e em seguida acrescentando-se o chumbo. As espessuras de atenuador utilizadas para essas medidas foram $0 ; 0,3 ; 0,6 ; 1,2 ; 1,8 ; 2,4 \mathrm{~cm}$.

Para cada situação foram realizadas 3 medidas com 300 UM.

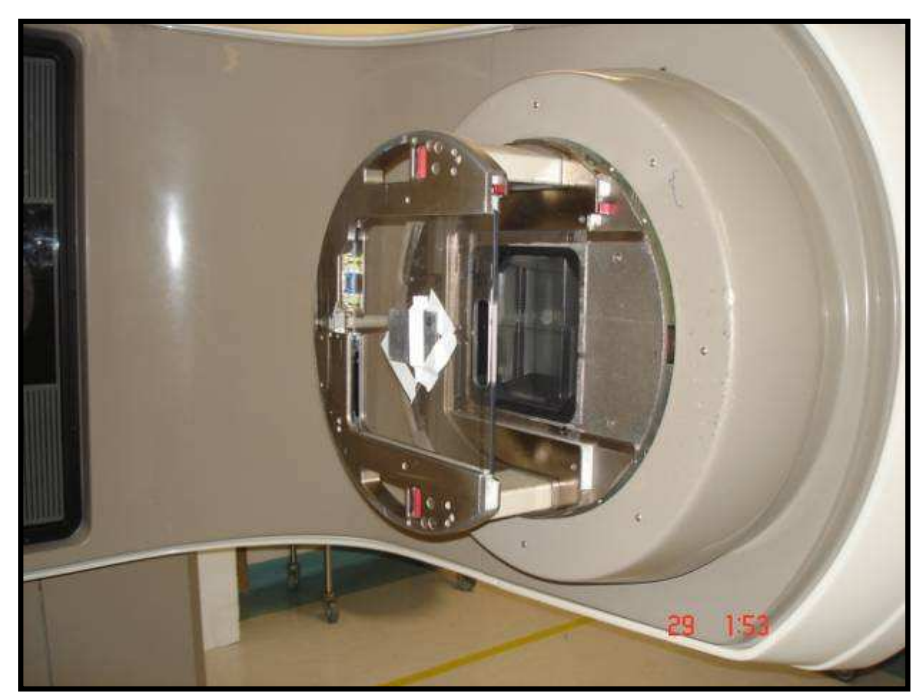

FIGURA 12- Posicionamento das placas de Pb para medida de CSR 
Para a determinação do coeficiente de atenuação linear do cerrobend foi utilizado um tamanho de campo de $4 \times 4 \mathrm{~cm}^{2}$ e a câmara foi posicionada no ar (com capa de equilíbrio eletrônico para energia de $6 \mathrm{MV}$ ) na distância fonte superfície de $332 \mathrm{~cm}$. Os atenuadores de cerrobend foram posicionados próximos a câmara de ionização representando a posição utilizada para tratamento (FIG. 13). Foram utilizadas espessuras de cerrobend de 0 a $2,5 \mathrm{~cm}$, num intervalo de $0,5 \mathrm{~cm}$.

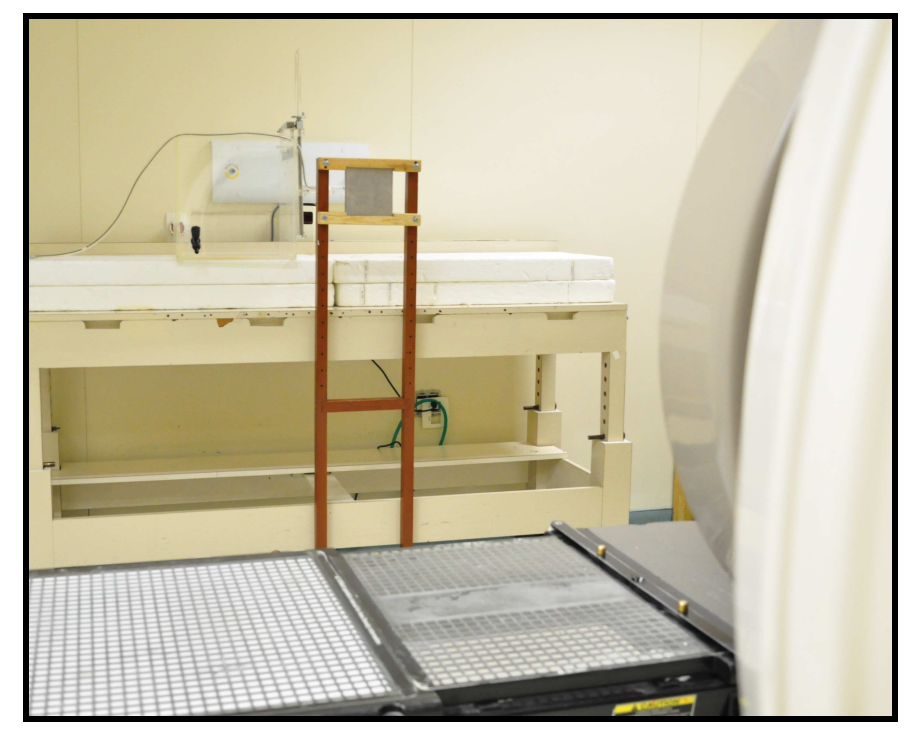

FIGURA 13- Posicionamento das placas de cerrobend para medida de CSR

Para cada situação foram realizadas 3 medidas com 300 UM.

As escolhas dos tamanhos de campo para as medidas de CSR foram feitas de forma a representar um feixe estreito, sendo que os atenuadores colimavam todo o campo de radiação.

Para determinação da transmissão da bandeja foi utilizada a mesma configuração de medida da CSR, retirando-se os atenuadores da frente do feixe e utilizando um tamanho de campo de $40 \times 40 \mathrm{~cm}^{2}$. Foram feitas 3 medidas reprodutíveis com e sem a placa de acrílico.

\subsubsection{Determinação da dose fora do raio central (OAR)}

Para as medidas de distribuição de dose fora do raio central o esquema de irradiação foi mantido o mesmo, cabeçote a $90^{\circ}$ e colimador a $45^{\circ}$. 
Como objeto simulador foram utilizadas placas de água sólida $\left(30 \times 30 \times 1 \mathrm{~cm}^{3}\right)$ mais 2 objetos simuladores de água com dimensões $30 \times 30 \times 30 \mathrm{~cm}^{3}$, um de cada lado para reproduzir espalhamento de acordo com a FIG. 14. As medidas foram realizadas nas distâncias de $0,10,15,20,30,40,50$ e $70 \mathrm{~cm}$ em relação ao raio central e nas profundidades de 5 e $10 \mathrm{~cm}$. Para as irradiações foram utilizadas $100 \mathrm{UM}$, taxa de dose de $320 \mathrm{UM} / \mathrm{min}$, e a distância da fonte até a superfície no raio central foi $292,4 \mathrm{~cm}$. O conjunto dosimétrico utilizado para essas medidas foi um câmara de ionização cilíndrica Scanditronix FC65-P de 0,65 cm e eletrômetro DOSE 1-IBA. A tensão de operação utilizada no eletrômetro foi -300 V. Para cada ponto foram realizadas 3 medidas.

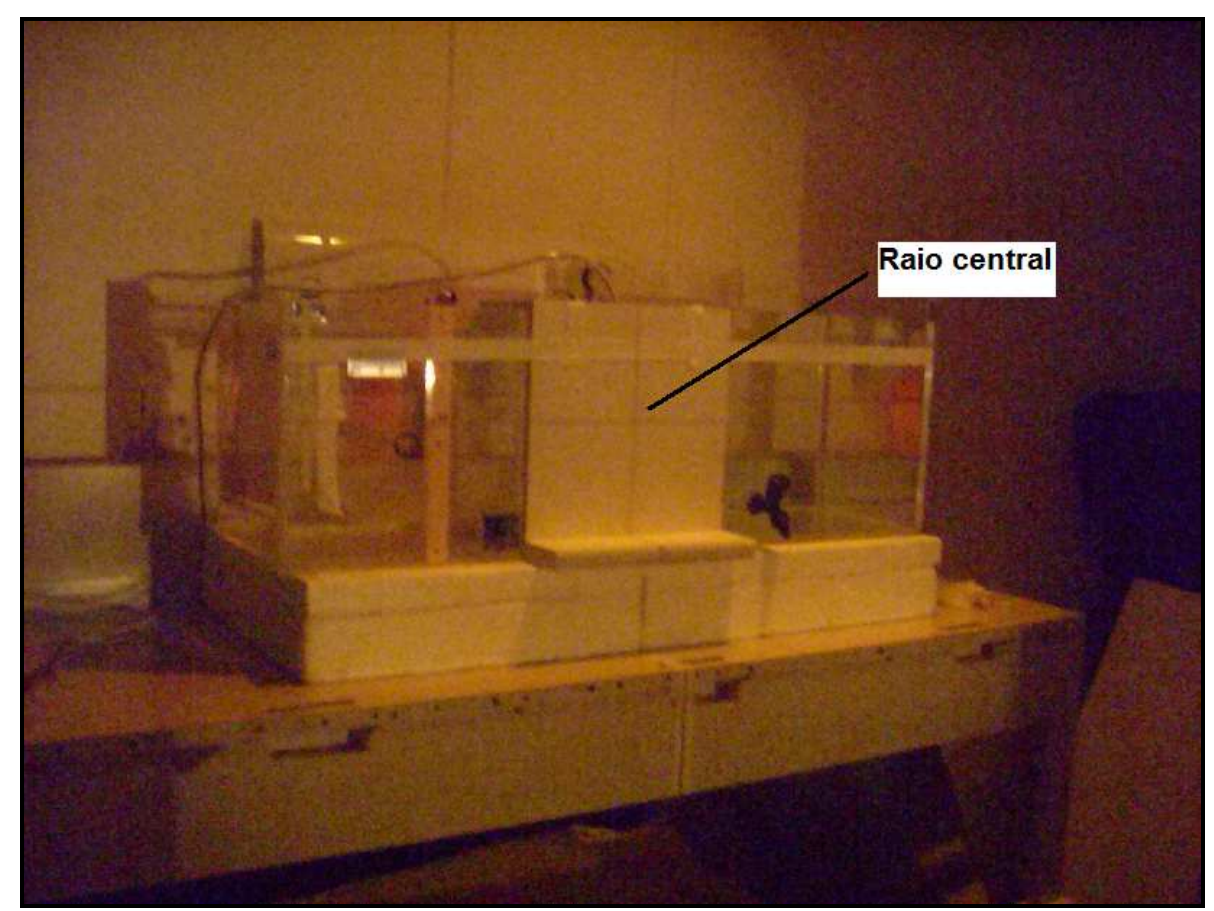

FIGURA 14- Esquema de irradiação para obtenção da dose fora do raio central.

\subsection{Calibração dos instrumentos para medidas in vivo}

Dois tipos de instrumentos dosimétricos foram calibrados para utilização em medidas in vivo para TBI: dosímetros termoluminescentes LiF:Mg,Ti

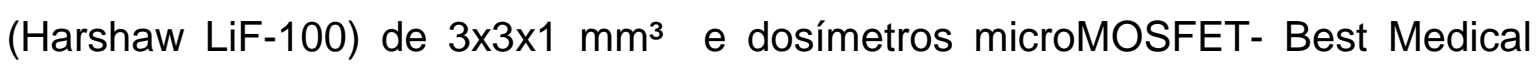
Canada. 


\subsubsection{Dosímetros termoluminescentes LiF:Mg, $\mathrm{Ti}$}

\subsubsection{Seleção dos TLDs}

A utilização de dosímetros termoluminescentes requer uma seleção prévia dos mesmos. Para isso, foram realizados 8 ciclos dosimétricos ${ }^{2}$ de um lote com 60 dosímetros previamente identificados com uma dose de 1,04 Gy. As irradiações foram realizadas num feixe de $6 \mathrm{MV}$ no aparelho 600C-Varian. Os parâmetros utilizados para essa exposição foram cabeçote e colimador a $0^{\circ}$, tamanho de campo 20x20 cm², distância da fonte até a superfície de $100 \mathrm{~cm}$ e 1,5 $\mathrm{cm}$ de profundidade. Os dosímetros foram posicionados sempre da mesma forma numa placa de acrílico de acordo com a FIG. 15. Foram utilizadas 5 placas de água sólida sob a placa de acrílico e 1,5 cm de cera sobre os TLDs (material utilizado para gerar a condição de equilíbrio eletrônico).

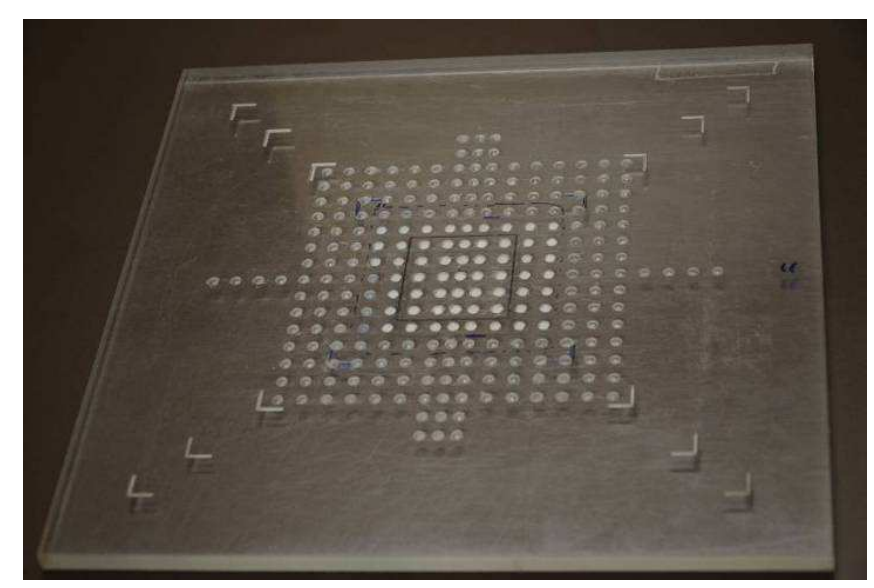

FIGURA 15- Esquema de posicionamento dos dosímetros termoluminescentes para seleção dos mesmos.

Para aquisição da resposta dos dosímetros termoluminescentes foi utilizada uma leitora de TL Harshaw modelo 3500 e o sistema de avaliação WinREMS- Thermo Electron Corporation. Durante o processo de leitura do sinal $\mathrm{TL}$, a leitora é pré-aquecida atingindo a temperatura de $50^{\circ} \mathrm{C}$ e para a aquisição do sinal há um aquecimento controlado de $50{ }^{\circ} \mathrm{C}$ até $300^{\circ} \mathrm{C}$ a uma taxa de $10^{\circ} \mathrm{C}$ por segundo. O resfriamento é feito com gás nitrogênio.

\footnotetext{
${ }^{2}$ Um ciclo dosimétrico corresponde ao tratamento térmico pré-irradiação, irradiação e leitura.
} 


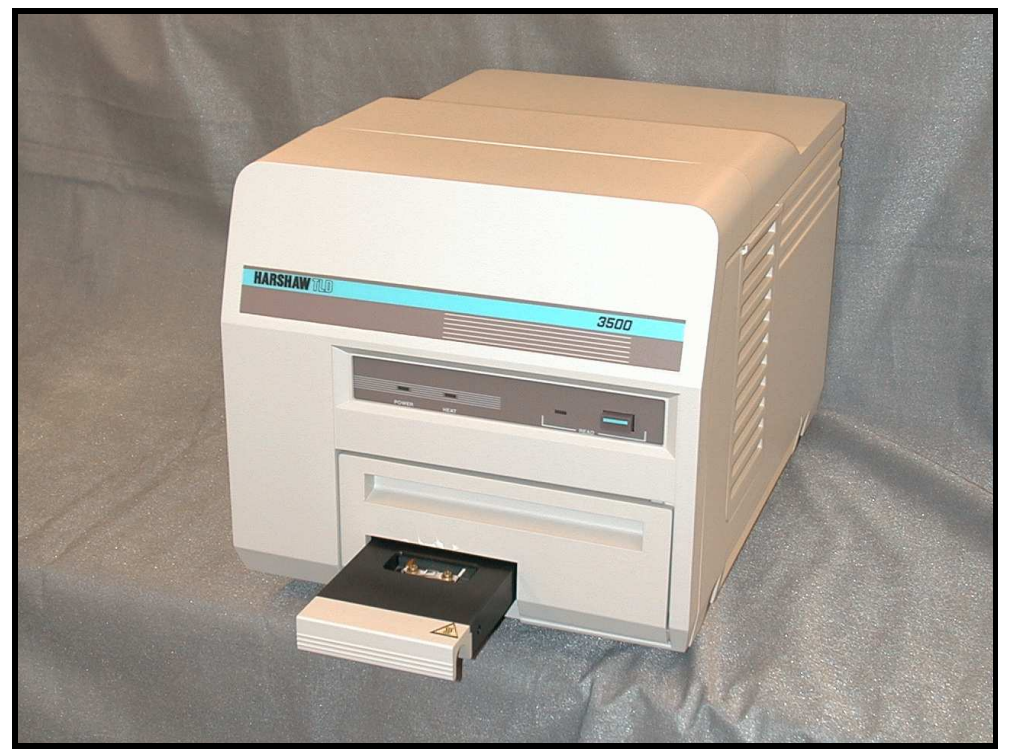

FIGURA 16- Leitora de TLDs Harshaw modelo 3500.

Após cada irradiação e leitura, os dosímetros foram submetidos a um tratamento térmico feito num forno dedicado Fisher Scientific, modelo 58. O ciclo de tratamento térmico consistiu de um aquecimento das pastilhas a $100{ }^{\circ} \mathrm{C}$ por duas horas (tratamento térmico pré-irradiação a baixa temperatura) e $400{ }^{\circ} \mathrm{C}$ por uma hora (tratamento térmico pré-irradiação a alta temperatura) (Da Rosa, 2000).

Uma vez realizados os ciclos dosimétricos, determinou-se a média, o desvio padrão e o coeficiente de variação das 4 últimas leituras individuais de cada dosímetro por meio das equações 8,9 e 10 respectivamente. A média aritmética é a melhor estimativa disponível do valor esperado de uma grandeza $q$ que varia aleatoriamente e para a qual $n$ observações independentes $q_{k}$ foram obtidas sob as mesmas condições de medição:

$$
\bar{q}=\frac{1}{n} \sum_{k=1}^{n} q_{k}
$$

O desvio padrão é a média quadrática dos desvios em relação à média aritmética de uma distribuição de freqüências. Ele pode ser usado para descrever a quantidade de dispersão na distribuição da freqüência.

$$
\sigma\left(q_{k}\right)=\sqrt{\frac{1}{n-1} \sum_{k=1}^{n}\left(q_{k}-\bar{q}\right)^{2}}
$$

Outra forma de expressar a variação dos dados é através do coeficiente de variação. Ele é interpretado como a variação dos dados em relação à média. 


$$
C V=\frac{\sigma\left(q_{k}\right)}{\bar{q}} * 100
$$

\subsubsection{Calibração dos dosímetros termoluminescentes LiF:Mg,Ti}

Foi realizada a calibração com 5 dosímetros (dos que apresentaram coeficiente variacional < 1\%). Os dosímetros foram posicionadas numa bandeja de acrílico de acordo com a FIG. 15, porém numa profundidade de 1,5 cm, campo $40 \times 40 \mathrm{~cm}^{2}$, distância da fonte até a superfície de $321 \mathrm{~cm}$, com o cabeçote angulado a $90^{\circ} \mathrm{e}$ colimador com ângulo de $45^{\circ}$ (condi ções utilizadas clinicamente para $\mathrm{TBI}$ ). Os dosímetros foram posicionados no centro do campo e irradiados com 1500 UM numa taxa de dose de $80 \mathrm{UM} / \mathrm{min}$.

\subsubsection{Calibração dos dosímetros microMOSFETs}

Para a calibração dos dosímetros microMOSFET, o cabeçote do aparelho foi angulado a $90^{\circ}$ para que a projeção do feixe fosse na horizontal (na parede). Os dosímetros foram posicionados de forma que ficassem perpendiculares ao feixe no raio central na distância fonte-superfície de $321 \mathrm{~cm} \mathrm{e}$ tamanho de campo $40 \times 40 \mathrm{~cm}^{2}$. Os dosímetros foram presos a uma bandeja numa profundidade de $1,5 \mathrm{~cm}$ e foram utilizados $6 \mathrm{~cm}$ na parte posterior dos detectores para gerar a condição de espalhamento (FIG. 17). Foram realizadas 3 irradiações com 362 UM e taxa de dose de 80UM/min.

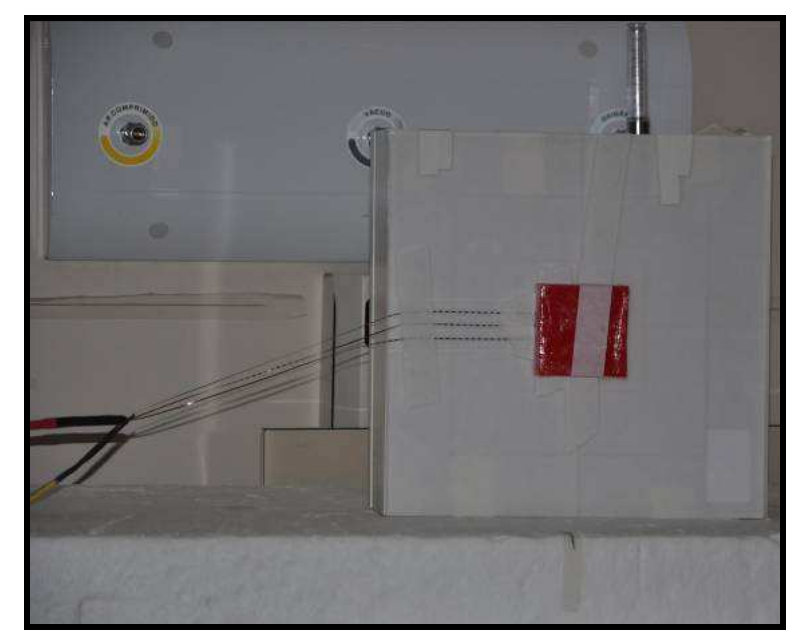

FIGURA 17- Esquema de irradiação para calibração dos dosímetros mMOSFETs. 


\subsection{Simulação de tratamento}

A simulação do tratamento foi realizada com o objeto simulador Alderson Rando, o qual foi posicionado da mesma forma como os pacientes são posicionados para tratamento (FIG. 18). A posição usual é decúbito lateral, próximo a parede, sendo utilizado o tamanho de campo $(40 \times 40) \mathrm{cm}$ (no isocentro). O cabeçote é angulado a $90^{\circ}$ e o colimad or a $45^{\circ}$ de forma que a projeção do campo luminoso alcance toda a dimensão do paciente. A taxa de dose utilizada durante a irradiação é a menor disponível no aparelho, ou seja, 80 $\mathrm{UM} / \mathrm{min}$, sendo que a taxa de dose na distância de tratamento encontra-se entre 5 e $10 \mathrm{cGy} / \mathrm{min}$ (AAPM, 1986).

Uma placa de acrílico de $0,5 \mathrm{~cm}$ de espessura é colocada próxima a região da superfície da pele do paciente a fim de superficializar a dose e retirar do feixe os fótons de baixa energia.

Em razão do objeto simulador ser composto somente por cabeça, pescoço e tronco, as pernas foram simuladas com garrafas pet preenchidas com água. Todos os diâmetros e distâncias necessários para cálculo foram medidos.

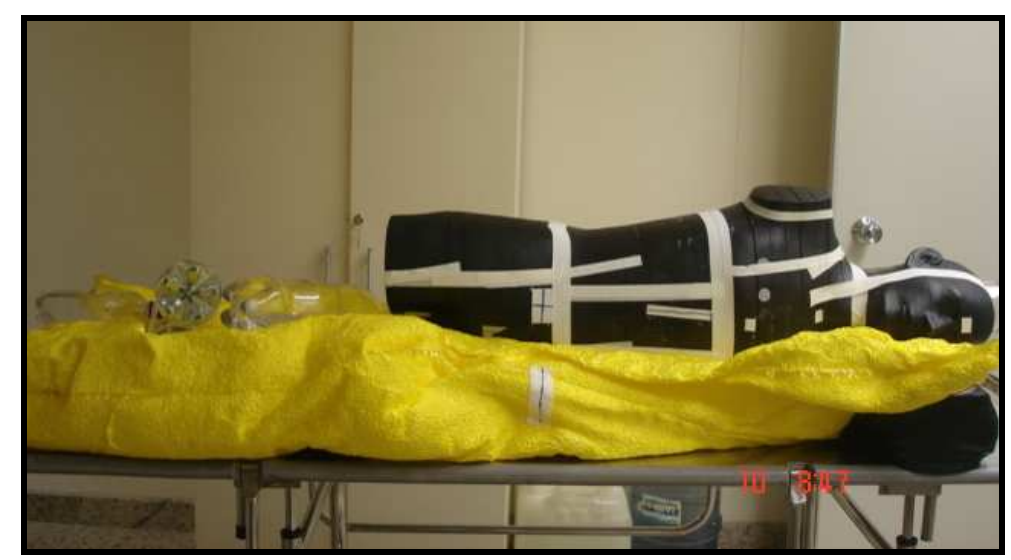

FIGURA 18- Posicionamento do objeto simulador Alderson Rando para simulação do tratamento.

Foram utilizados três tipos de dosímetros para as medidas de dose de entrada no objeto simulador, câmara de ionização cilíndrica Scanditronix FC65-P (com capa de build-up) e eletrômetro DOSE 1-IBA (tensão de operação -300 V), microMOSFETs e dosímetros termoluminescentes (LiF:Mg,Ti). Os detectores foram posicionados em sete pontos no objeto simulador: cabeça, pescoço, tórax, tórax sob o bloco de pulmão, raio central, joelho e pé. 


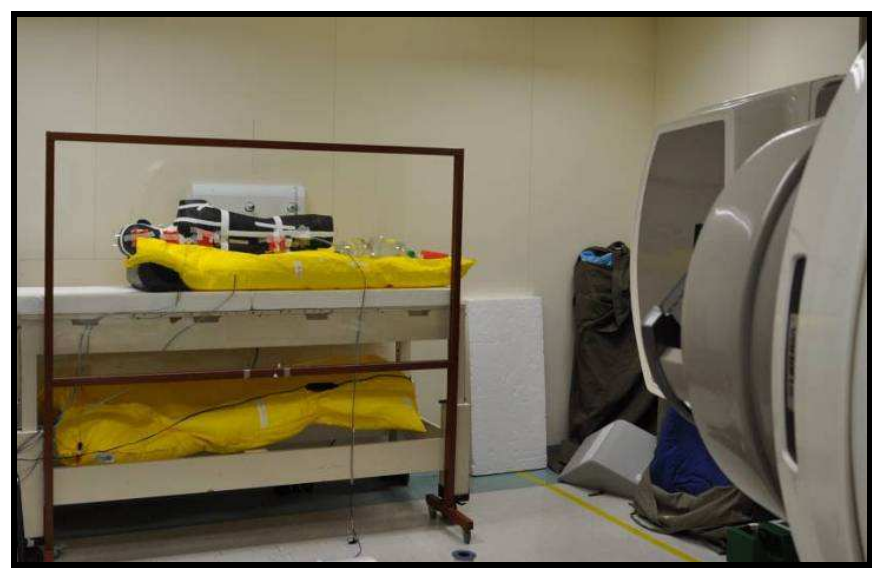

FIGURA 19- Posicionamento dos detectores durante a simulação do tratamento.

O objeto simulador foi irradiado com uma dose de 2 Gy, calculada para o raio central no meio do diâmetro ântero-posterior. Essa dose foi entregue na metade da posição AP e na metade da posição PA.

Durante a simulação do tratamento foram utilizados 3 TLDs em cada ponto de estudo. Para a câmara de ionização foram feitas 2 leituras de cada ponto e para os MOSFETs foi realizada somente uma leitura em cada ponto de medida. 


\section{RESULTADOS E DISCUSSÕES}

\subsection{Comissionamento do acelerador linear para implementação de TBI}

Pelo fato de haver um grande número de medidas para serem realizadas com a câmara de ionização, optou-se em fazê-las com uma taxa de dose superior aquela utilizada para tratamento. Para isso foi verificada a resposta da câmara de ionização nas taxas de dose 80, 160 e 320 UM/min com o mesmo esquema e posicionamento da calibração absoluta. Para cada taxa de dose foram realizadas três medidas com 100 UM.

As leituras obtidas a partir da irradiação da câmara de ionização com diferentes taxas de dose encontram-se apresentadas na TAB. 4.

TABELA 4- Leituras obtidas a partir da irradiação da câmara de ionização com diferentes taxas de dose.

\begin{tabular}{cccccc}
\hline $\begin{array}{c}\text { Taxa de dose } \\
(\mathbf{U M} / \mathbf{m i n})\end{array}$ & $\mathbf{L 1}(\eta C)$ & $\mathbf{L 2}(\eta C)$ & $\mathbf{L 3}(\eta C)$ & $\begin{array}{c}\mathbf{L} \text { médio } \\
(\eta C)\end{array}$ & $\sigma(\eta C)$ \\
\hline $\mathbf{8 0}$ & 1,903 & 1,903 & 1,903 & 1,903 & 0,000 \\
$\mathbf{1 6 0}$ & 1,902 & 1,901 & 1,902 & 1,902 & 0,001 \\
$\mathbf{3 2 0}$ & 1,902 & 1,901 & 1,902 & 1,902 & 0,001 \\
\hline
\end{tabular}

Como já era esperada, a carga gerada na câmara de ionização não sofre variação significativa com diferentes taxas de dose. A partir disso pode-se fazer a aquisição das medidas com a taxa de dose de $320 \mathrm{UM} / \mathrm{min}$, o que torna mais rápida a obtenção dos dados.

Para os dosímetros termoluminescentes LiF:Mg,Ti foi observada uma variação de $3 \%$ comparando-se as taxas de dose de $80 \mathrm{UM} / \mathrm{min}$ e $320 \mathrm{UM} / \mathrm{min}$ o que tornou necessário realizar as medidas com as taxas de dose utilizadas clinicamente para TBI. O mesmo deve ser feito com os dosímetros microMOSFET. Por eles apresentarem um erro maior na reprodutibilidade em taxas de dose mais altas, o ideal é que as medidas sejam feitas na taxa de dose utilizada na prática (Resende et al., 2010).

\subsubsection{Obtenção dos dados de Percentual de Dose Profunda}

Os valores de Percentual de Dose Profunda sem a placa de acrílico (utilizada para superficializar a dose) encontram-se apresentados na FIG. 20. 
Esses valores estão normalizados para a profundidade de 1,2 cm (profundidade de máximo nessa condição). As barras de erro não podem ser visualizadas, pois são menores que os pontos dos gráficos.

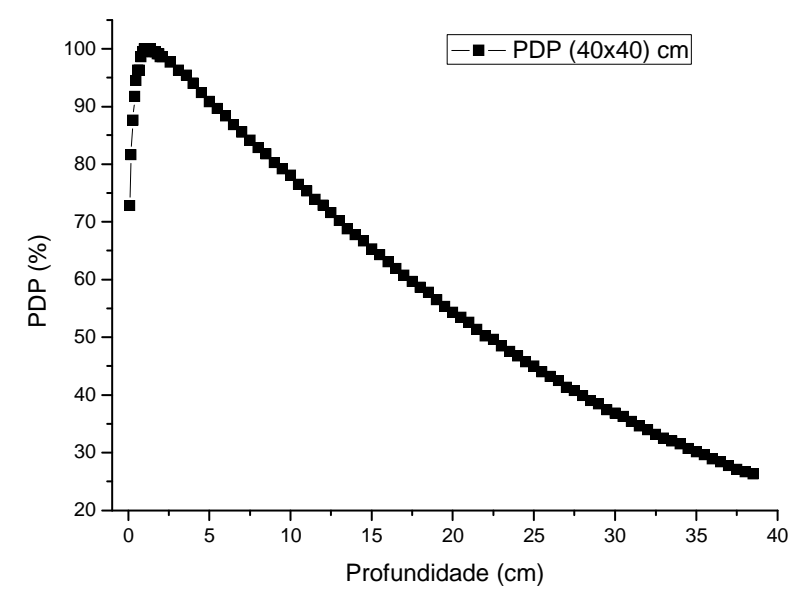

FIGURA 20- Percentual de Dose Profunda para as condições de TBI (sem a placa de acrílico).

Os valores de Percentual de Dose Profunda com a placa de acrílico (utilizada para superficializar a dose) encontram-se apresentados na FIG. 21. Esses valores estão normalizados para a superfície (profundidade de máximo nessa condição).

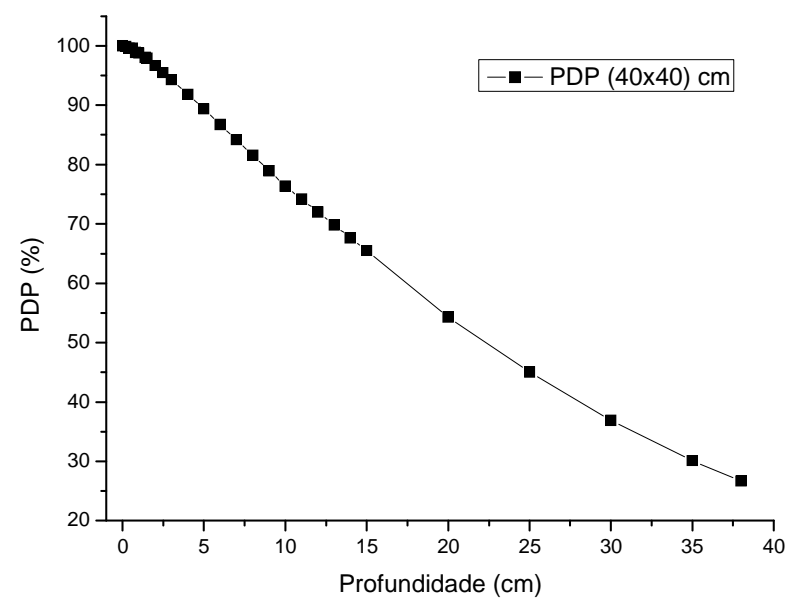

FIGURA 21- Percentual de Dose Profunda para as condições de TBI (com a placa de acrílico). 
Sobrepondo as duas curvas (FIG. 22) pode-se observar que há uma mudança na forma da curva de PDP principalmente próximo a superfície do paciente. Essa mudança se deve a utilização da placa de acrílico.

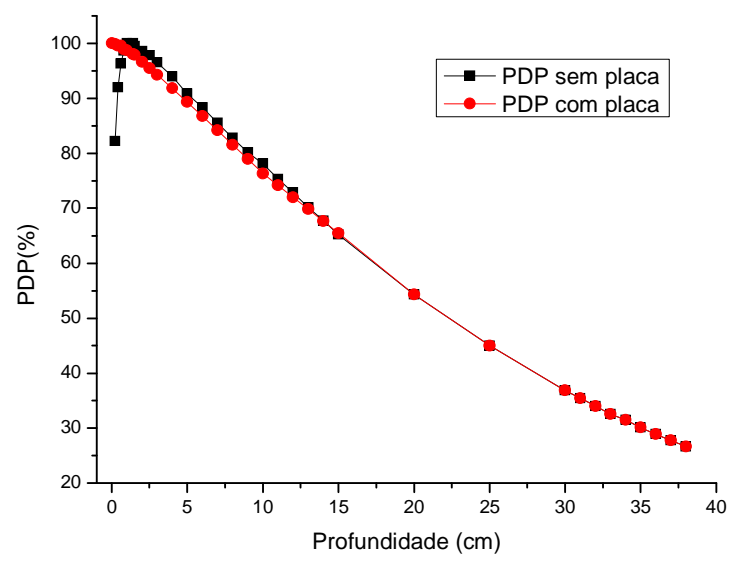

FIGURA 22- Comparação das curvas de Percentual de Dose Profunda nas condições de TBI (com e sem a placa de acrílico).

Os valores de Percentual de Dose Profunda encontram-se também apresentados em forma de tabela (TAB. 5).

TABELA 5- Valores de PDP medidos com e sem a placa de acrílico.

\begin{tabular}{ccc|ccc}
\hline $\begin{array}{c}\text { Profundidade } \\
(\mathrm{cm})\end{array}$ & Sem placa & Com placa & $\begin{array}{c}\text { Profundidade } \\
(\mathrm{cm})\end{array}$ & Sem placa & Com placa \\
\hline 0 & & 100,00 & 7 & 85,54 & 84,20 \\
0,2 & 82,20 & 99,94 & 8 & 82,82 & 81,58 \\
0,4 & 91,98 & 99,59 & 9 & 80,21 & 78,95 \\
0,6 & 96,30 & 99,59 & 10 & 78,09 & 76,33 \\
0,8 & 98,69 & 98,88 & 11 & 75,35 & 74,17 \\
1 & 100,00 & 98,76 & 12 & 72,87 & 72,00 \\
1,4 & 100,00 & 98,06 & 13 & 70,19 & 69,83 \\
1,5 & 99,50 & 97,88 & 14 & 67,73 & 67,67 \\
2 & 98,60 & 96,68 & 15 & 65,25 & 65,50 \\
2,5 & 97,86 & 95,49 & 20 & 54,31 & 54,31 \\
3 & 96,55 & 94,29 & 25 & 44,99 & 44,99 \\
4 & 94,00 & 91,82 & 30 & 36,88 & 36,88 \\
5 & 90,82 & 89,35 & 35 & 30,13 & 30,13 \\
6 & 88,33 & 86,77 & & & \\
\hline
\end{tabular}




\subsubsection{Calibração absoluta}

A leitura média obtida a partir das irradiações da câmara foi 1,902 $\eta C \pm 0,001$.

A partir das equações 4 e 5 obteve-se que o valor de dose para o ponto de medida é 12,64 \pm 0,01 cGy. E aplicando-se a equação 6 encontramos o fator de calibração para esse feixe nas condição descritas acima. $O$ fator de calibração encontrado foi 0,1264 cGy/UM.

O fator de calibração para os tratamentos convencionais (distância de $100 \mathrm{~cm}$ e profundidade de dose máxima) é 1cGy/UM. Ou seja, nos tratamentos de irradiação de corpo inteiro são necessárias muito mais UM para que a mesma dose seja obtida.

\subsubsection{Transmissão da bandeja e CSR dos atenuadores}

Os valores de transmissão nas medidas de CSR do $\mathrm{Pb}$ encontram-se apresentados na TAB. 6.

TABELA 6- CSR do Pb nas condições de TBI.

\begin{tabular}{|c|c|c|c|c|c|}
\hline $\begin{array}{c}\text { Espessura Pb } \\
\mathbf{( c m})\end{array}$ & $\mathbf{L 1}(\mathbf{n C})$ & L2 (nC) & $\mathbf{L 3 ~ ( n C )}$ & $\begin{array}{c}\text { L média } \\
\mathbf{( n C )}\end{array}$ & $\sigma \mathbf{( n C )}$ \\
\hline $\mathbf{0 , 0}$ & 4,801 & 4,802 & 4,802 & 4,802 & 0,001 \\
\hline $\mathbf{0 , 3}$ & 4,044 & 4,045 & 4,045 & 4,045 & 0,001 \\
\hline $\mathbf{0 , 6}$ & 3,378 & 3,378 & 3,377 & 3,378 & 0,001 \\
\hline $\mathbf{1 , 2}$ & 2,374 & 2,374 & 2,374 & 2,374 & 0,000 \\
\hline $\mathbf{1 , 8}$ & 1,665 & 1,666 & 1,667 & 1,666 & 0,001 \\
\hline $\mathbf{2 , 4}$ & 1,179 & 1,180 & 1,180 & 1,180 & 0,001 \\
\hline
\end{tabular}

A partir dos valores medidos pode-se observar que a camada semiredutora do chumbo nas condições de TBI é $1,2 \mathrm{~cm}$, o que está de acordo com os valores utilizados atualmente. Dessa forma, a partir da equação [7] o valor do coeficiente de atenuação linear é $0,578 / \mathrm{cm}$. 
As medidas para determinação da CRS do cerrobend encontram-se apresentados na TAB. 7.

TABELA 7- CSR do cerrobend nas condições de TBI.

\begin{tabular}{|c|c|c|c|c|c|}
\hline $\begin{array}{c}\text { Espessura } \\
\text { cerrobend } \mathbf{( c m})\end{array}$ & L1 (nC) & L2 (nC) & L3 (nC) & $\begin{array}{c}\text { L média } \\
\mathbf{( n C )}\end{array}$ & $\sigma$ (nC) \\
\hline $\mathbf{0 , 0}$ & 4,955 & 4,953 & 4,954 & 4,954 & 0,001 \\
\hline $\mathbf{0 , 5}$ & 4,065 & 4,066 & 4,065 & 4,065 & 0,001 \\
\hline $\mathbf{1 , 0}$ & 3,384 & 3,382 & 3,382 & 3,383 & 0,001 \\
\hline $\mathbf{1 , 5}$ & 2,809 & 2,809 & 2,810 & 2,809 & 0,001 \\
\hline $\mathbf{2 , 0}$ & 2,314 & 2,315 & 2,315 & 2,315 & 0,001 \\
\hline $\mathbf{2 , 5}$ & 1,893 & 1,893 & 1,894 & 1,893 & 0,001 \\
\hline
\end{tabular}

A partir dos valores medidos pode-se observar que a camada semiredutora do cerrobend nas condições de TBI foi de 1,8 cm. Dessa forma, a partir da equação [7] o valor do coeficiente de atenuação linear é 0,385/cm. O valor de CSR desse material utilizado atualmente para os tratamentos de TBI é 1,5 cm.

Em relação as medidas realizadas para determinação da transmissão da bandeja, a média dos valores encontrados sem nada interpondo o feixe foi $5,598 \pm 0,002$ nC. Para as medidas com a bandeja interpondo o feixe, os valores encontrados foram 5,330 $\pm 0,003$ nC. Sendo assim o fator bandeja é 0,952.

\subsubsection{Determinação da dose fora do raio central}

Os dados de dose fora do raio central foram medidos em duas profundidades, 5 e $10 \mathrm{~cm}$. Para cada profundidade e distância em relação ao raio central foram realizadas três medidas. Os valores encontram-se na TAB. 8 e TAB. 9. 
TABELA 8- OAR obtidos a partir da variação da distância em relação ao raio central para profundidade de $10 \mathrm{~cm}$.

\begin{tabular}{ccccccc}
\hline $\mathbf{d}(\mathbf{c m})$ & $\mathbf{L} \mathbf{1}(\eta C)$ & $\mathbf{L} \mathbf{(}(\eta C)$ & $\mathbf{L 3}(\eta C)$ & $\begin{array}{c}\text { L médio } \\
(\eta C)\end{array}$ & $\sigma(\eta C)$ & OAR \\
\hline $\mathbf{0}$ & 1,457 & 1,458 & 1,461 & 1,459 & 0,002 & 1,000 \\
$\mathbf{1 0}$ & 1,483 & 1,485 & 1,485 & 1,484 & 0,001 & 1,018 \\
$\mathbf{1 5}$ & 1,499 & 1,499 & 1,499 & 1,499 & 0,000 & 1,028 \\
$\mathbf{2 0}$ & 1,507 & 1,507 & 1,507 & 1,507 & 0,000 & 1,033 \\
$\mathbf{3 0}$ & 1,515 & 1,516 & 1,519 & 1,517 & 0,002 & 1,040 \\
$\mathbf{4 0}$ & 1,520 & 1,520 & 1,521 & 1,520 & 0,001 & 1,042 \\
$\mathbf{5 0}$ & 1,518 & 1,518 & 1,519 & 1,518 & 0,001 & 1,041 \\
$\mathbf{7 0}$ & 1,492 & 1,492 & 1,492 & 1,492 & 0,000 & 1,023 \\
\hline
\end{tabular}

$\mathrm{d}(\mathrm{cm})=$ distância em relação ao raio central

TABELA 9- OAR obtidos a partir da variação da distância em relação ao raio central para profundidade de $5 \mathrm{~cm}$.

\begin{tabular}{ccccccc}
\hline $\mathbf{d}(\mathbf{c m})$ & $\mathbf{L} \mathbf{1}(\eta C)$ & $\mathbf{L} \mathbf{2}(\eta C)$ & $\mathbf{L 3}(\eta C)$ & $\begin{array}{c}\mathbf{L} \text { médio } \\
(\eta C)\end{array}$ & $\sigma(\eta C)$ & OAR \\
\hline $\mathbf{0}$ & 1,707 & 1,707 & 1,709 & 1,708 & 0,001 & 1,000 \\
$\mathbf{1 0}$ & 1,732 & 1,731 & 1,733 & 1,732 & 0,001 & 1,014 \\
$\mathbf{1 5}$ & 1,753 & 1,752 & 1,750 & 1,752 & 0,002 & 1,026 \\
$\mathbf{2 0}$ & 1,762 & 1,763 & 1,764 & 1,763 & 0,001 & 1,032 \\
$\mathbf{3 0}$ & 1,777 & 1,774 & 1,772 & 1,774 & 0,003 & 1,039 \\
$\mathbf{4 0}$ & 1,787 & 1,789 & 1,786 & 1,787 & 0,002 & 1,047 \\
$\mathbf{5 0}$ & 1,793 & 1,796 & 1,797 & 1,795 & 0,002 & 1,051 \\
$\mathbf{7 0}$ & 1,784 & 1,783 & 1,787 & 1,785 & 0,002 & 1,045 \\
\hline
\end{tabular}

$\mathrm{d}(\mathrm{cm})=$ distância em relação ao raio central

A FIG. 23 mostra o perfil do feixe para o campo $40 \times 40 \mathrm{~cm}^{2}$. $\mathrm{O}$ abaulamento da curva no raio central do feixe ocorre em virtude do filtro aplainador e deve ser corrigido. Os valores de fator off axis encontram-se normalizados para a dose no raio central. 


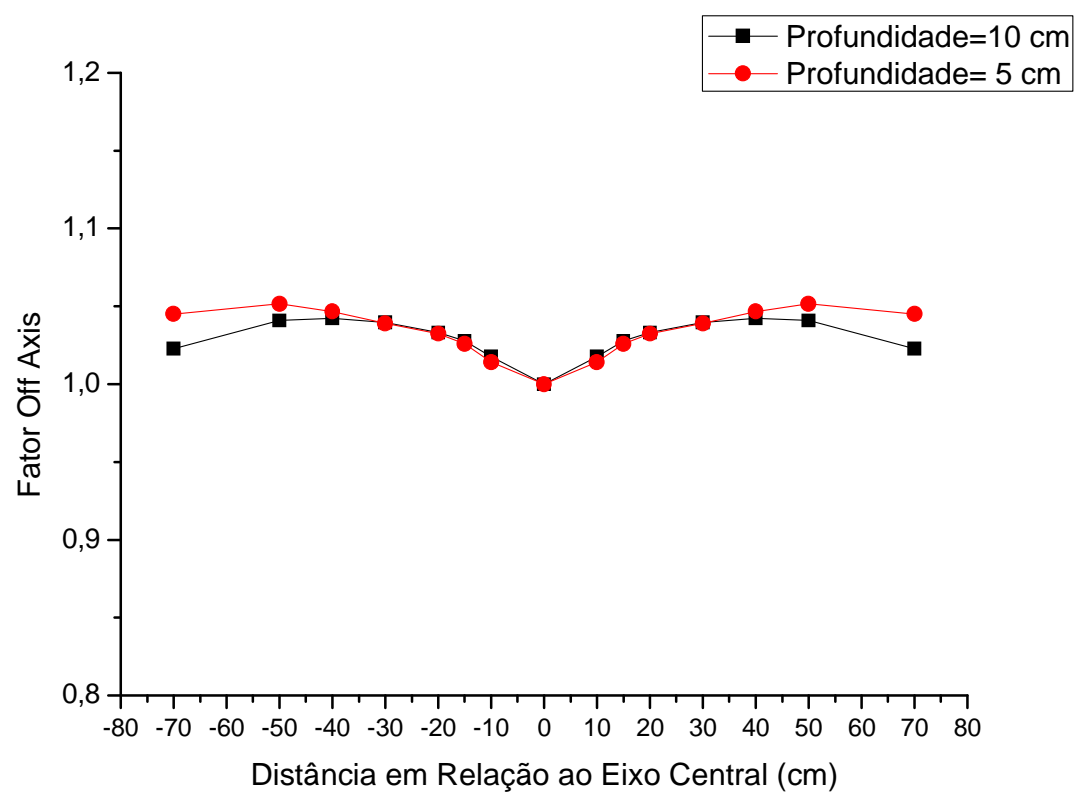

FIGURA 23- Fatores de correção para dose fora do raio central.

\subsection{Calibração dos instrumentos para medidas in vivo}

\subsubsection{Dosímetros termoluminescentes LiF:Mg,Ti}

\subsubsection{Seleção dos TLDs}

As leituras médias $\left(L_{\text {media }}\right)$, desvio padrão $(\eta C)$ e coeficiente de variação (\%) obtidos a partir dos oito ciclos dosimétricos estão apresentados na TAB. 10. Os dosímetros selecionados para calibração encontram-se destacados na tabela. Foram selecionados os TLDs em que $\sigma \leq 3 \eta C$ e $\mathrm{CV}<1 \%$ nas últimas 4 leituras.

Somente foram utilizadas as 4 últimas leituras para realização da média, desvio padrão e coeficiente de variação porque durante os procedimentos de calibração foi realizada a troca do tubo acelerador que estava sendo utilizado para calibração. 
TABELA 10- Valores obtidos a partir dos procedimentos de seleção dos dosímetros termoluminescentes.

\begin{tabular}{|c|c|c|c|c|c|c|c|}
\hline TLD & $L_{\text {media }}(\eta C)$ & $\sigma(\eta C)$ & CV (\%) & TLD & $L_{\text {media }}(\eta C)$ & $\sigma(\eta C)$ & CV (\%) \\
\hline 1 & 353,05 & 2,9 & 0,8 & 29 & 340,30 & 2,5 & 0,7 \\
\hline 2 & 417,05 & 1,5 & 0,4 & 30 & 351,75 & 0,5 & 0,1 \\
\hline 3 & 377,15 & 2,9 & 0,8 & 31 & 334,40 & 3,3 & 1,0 \\
\hline 4 & 421,60 & 2,1 & 0,5 & 32 & 327,30 & 1,4 & 0,4 \\
\hline 5 & 365,20 & 15,3 & 4,2 & 33 & 342,55 & 1,3 & 0,4 \\
\hline 6 & 409,20 & 2,1 & 0,5 & 34 & 328,85 & 1,5 & 0,5 \\
\hline 7 & 384,25 & 1,5 & 0,4 & 35 & 375,40 & 0,3 & 0,1 \\
\hline 8 & 351,40 & 2,1 & 0,6 & 36 & 338,60 & 0,6 & 0,2 \\
\hline 9 & 355,95 & 1,8 & 0,5 & 37 & 338,70 & 3,8 & 1,1 \\
\hline 10 & 302,85 & 1,1 & 0,4 & 38 & 334,55 & 4,3 & 1,3 \\
\hline 11 & 356,35 & 0,1 & 0,0 & 39 & 346,65 & 1,6 & 0,5 \\
\hline 12 & 366,25 & 2,5 & 0,7 & 40 & 354,75 & 2,8 & 0,8 \\
\hline 13 & 345,00 & 0,3 & 0,1 & 41 & 342,00 & 2,5 & 0,7 \\
\hline 14 & 350,85 & 1,6 & 0,5 & 42 & 357,95 & 0,5 & 0,1 \\
\hline 15 & 380,10 & 2,3 & 0,6 & 43 & 337,90 & 11,2 & 3,3 \\
\hline 16 & 358,85 & 3,9 & 1,1 & 44 & 345,05 & 0,1 & 0,0 \\
\hline 17 & 370,55 & 2,8 & 0,7 & 45 & 353,35 & 5,7 & 1,6 \\
\hline 18 & 376,65 & 2,5 & 0,7 & 46 & 316,10 & 6,1 & 1,9 \\
\hline 19 & 343,95 & 3,3 & 1,0 & 47 & 366,45 & 5,9 & 1,6 \\
\hline 20 & 355,90 & 4,8 & 1,4 & 48 & 303,30 & 5,7 & 1,9 \\
\hline 21 & 366,30 & 0,8 & 0,2 & 49 & 364,10 & 2,1 & 0,6 \\
\hline 22 & 330,70 & 0,0 & 0,0 & 50 & 350,60 & 4,7 & 1,3 \\
\hline 23 & 330,75 & 1,9 & 0,6 & 51 & 345,60 & 0,4 & 0,1 \\
\hline 24 & 341,65 & 0,1 & 0,0 & 52 & 343,75 & 4,7 & 1,4 \\
\hline 25 & 352,15 & 0,2 & 0,1 & 53 & 332,20 & 2,4 & 0,7 \\
\hline 26 & 359,45 & 1,3 & 0,4 & 54 & 347,00 & 1,7 & 0,5 \\
\hline 27 & 235,75 & 2,6 & 1,1 & 55 & 373,35 & 0,1 & 0,0 \\
\hline 28 & 344,20 & 0,4 & 0,1 & 56 & 351,45 & 0,4 & 0,1 \\
\hline
\end{tabular}

Os dosímetros 17 e 40 não foram utilizados pois não se mostraram reprodutíveis nos 4 primeiros ciclos dosimétricos. 


\subsubsection{Calibração dos dosímetros termoluminescentes LiF:Mg,Ti}

Para as condições de calibração era esperada uma dose de 156,7 cGy (valor calculado). A média dos valores de dose dos 5 dosímetros utilizados para essa medida foi 139,5 cGy $\pm 2,5$ cGy, o que gera uma discrepância de $-11 \%$ do valor esperado. Dessa forma, para as medidas nas condições do TBI o fator de calibração para os TLDs 1,11.

\subsubsection{Calibração dos dosímetros MOSFET}

Os resultados obtidos a partir da calibração dos dosímetros MOSFET encontram-se apresentados na TAB. 11.

TABELA 11- Fatores de calibração obtidos a partir da irradiação dos dosímetros mMOSFET

\begin{tabular}{|c|c|c|c|c|c|c|c|}
\hline MOSFET & Calib & $\begin{array}{c}\text { L inicial } \\
(\mathrm{mV})\end{array}$ & $\begin{array}{l}\text { L final } \\
(\mathrm{mV})\end{array}$ & $\begin{array}{c}\Delta \mathrm{L} \\
(\mathrm{mV})\end{array}$ & $\begin{array}{c}\sigma \\
(\mathrm{mV})\end{array}$ & $\begin{array}{c}F_{c a l} \\
\text { (mV/cGy) }\end{array}$ & $\begin{array}{c}\overline{F_{c a l}} \\
(\mathrm{mV} / \mathrm{cGy})\end{array}$ \\
\hline & 1 & 8353,04 & 8396,30 & 43,26 & & 1,14 & \\
\hline \multirow[t]{3}{*}{ M 1} & 2 & 8397,93 & 8440,54 & 42,61 & 0,55 & 1,13 & 1,14 \\
\hline & 3 & 8484,68 & 8528,39 & 43,71 & & 1,16 & \\
\hline & 1 & 11250,13 & 11293,52 & 43,39 & & 1,15 & \\
\hline \multirow[t]{3}{*}{ M 2} & 2 & 11310,42 & 11354,50 & 44,08 & 0,47 & 1,17 & 1,15 \\
\hline & 3 & 11412,20 & 11455,37 & 43,17 & & 1,14 & \\
\hline & 1 & 9545,53 & 9587,72 & 42,19 & & 1,12 & \\
\hline \multirow[t]{2}{*}{ M 3} & 2 & 9590,04 & 9629,89 & 39,85 & 1,60 & 1,05 & 1,10 \\
\hline & 3 & 9674,56 & 9717,48 & 42,92 & & 1,14 & \\
\hline
\end{tabular}

A dose utilizada para calibração foi 37,8 cGy. Não foi necessário empregar a dose usada clinicamente, pois esse dosímetro tem uma resposta linear com a dose (Resende et al., 2010) e também para prolongar o tempo de vida do mesmo.

Somente os MOSFETs 1 e 3 puderam ser utilizados nas medidas de dose de entrada do objeto simulador. O MOSFET 2 alcançou a tensão de saturação depois dos procedimentos de calibração no mesmo (20.000 mV). 


\subsection{Simulação de tratamento}

Os valores obtidos a partir das medidas feitas anteriormente foram aplicados na tabela utilizada na rotina clínica para cálculo de dose (TAB. 12).

TABELA 12- Valores utilizados para simulação do tratamento

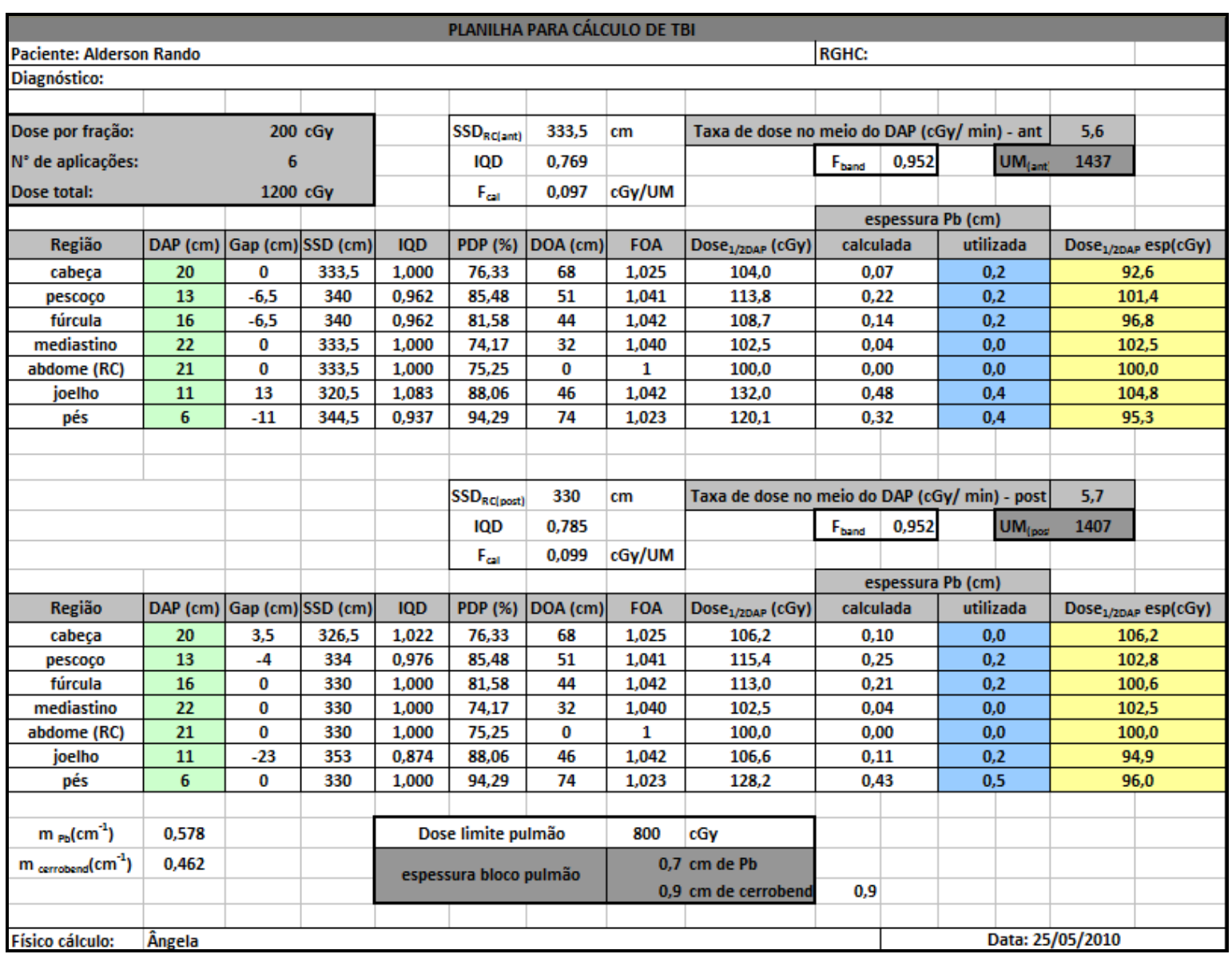

Como pode ser observado na TAB. 12, a taxa de dose no ponto de prescrição encontra-se entre 5 e 6 cGy/min, seguindo as recomendações do protocolo (AAPM, 1986). Da mesma forma, a homogeneidade nas regiões avaliadas está entre $\pm 10 \%$.

As doses de entrada obtidas com os diferentes detectores a partir da simulação do tratamento encontram-se apresentadas nas TAB. 13 e 14. 
TABELA 13- Medidas de dose de entrada do campo AP para diferentes detectores.

\begin{tabular}{|l|c|cc|cc|cc|}
\hline \multicolumn{10}{|c|}{ ANTERIOR } \\
\hline \multirow{2}{*}{ Região } & $\begin{array}{c}\text { Dose } \\
\text { Esperada } \\
\text { (cGy) }\end{array}$ & $\mathbf{C l}$ & $\begin{array}{c}\text { Desvio } \\
\text { (\%) }\end{array}$ & MOSFET & $\begin{array}{c}\text { Desvio } \\
(\%)\end{array}$ & TLD & $\begin{array}{c}\text { Desvio } \\
(\%)\end{array}$ \\
\hline Cabeça & 121,3 & $121,7 \pm 0,2$ & 0,3 & $123,6 \pm 0,3$ & 1,9 & $125,7 \pm 0,4$ & 3,6 \\
Pescoço & 118,6 & $123,1 \pm 0,3$ & 3,8 & $123,5 \pm 0,6$ & 4,1 & $129,3 \pm 1,3$ & 9,0 \\
Tórax & 138,2 & $139,5 \pm 0,2$ & 0,9 & $137,4 \pm 0,3$ & $-0,6$ & $135,8 \pm 1,0$ & $-1,8$ \\
Sob bloco & 91,2 & $90,3 \pm 0,1$ & $-1,0$ & $93,5 \pm 0,6$ & 2,5 & $91,4 \pm 0,3$ & 0,2 \\
RC & 132,9 & $135,3 \pm 0,1$ & 1,8 & $132,8 \pm 0,3$ & $-0,1$ & $131,0 \pm 0,7$ & $-1,5$ \\
Joelho & 119,0 & $115,2 \pm 0,0$ & $-3,2$ & $121,3 \pm 0,6$ & 1,9 & $116,6 \pm 1,5$ & $-2,0$ \\
Pé & 101,1 & $93,4 \pm 0,2$ & $-7,6$ & $99,6 \pm 0,3$ & $-1,5$ & $104,0 \pm 0,6$ & 2,9 \\
\hline
\end{tabular}

TABELA 14- Medidas de dose de entrada do campo PA para diferentes detectores.

\begin{tabular}{|c|c|c|c|c|c|c|c|}
\hline \multicolumn{8}{|c|}{ POSTERIOR } \\
\hline \multirow[b]{2}{*}{ Região } & \multirow{2}{*}{$\begin{array}{c}\text { Dose } \\
\text { Esperada } \\
\text { (cGy) }\end{array}$} & \multicolumn{5}{|c|}{ Doses de entrada (cGy) } & \multirow[b]{2}{*}{$\begin{array}{c}\text { Desvio } \\
(\%)\end{array}$} \\
\hline & & Cl & $\begin{array}{c}\text { Desvio } \\
(\%)\end{array}$ & MOSFET & $\begin{array}{c}\text { Desvio } \\
(\%)\end{array}$ & TLD & \\
\hline Cabeça & 139,1 & $136,1 \pm 0,1$ & $-2,2$ & $140,2 \pm 0,3$ & 0,8 & $142,2 \pm 0,7$ & 2,2 \\
\hline Pescoço & 120,3 & $124,2 \pm 0,0$ & 3,2 & $127,1 \pm 0,6$ & 5,7 & $127,1 \pm 0,6$ & 5,7 \\
\hline Tórax & 138,2 & $139,8 \pm 0,1$ & 1,2 & $141,8 \pm 0,3$ & 2,6 & $138,2 \pm 0,9$ & 0,0 \\
\hline Sob bloco & 91,2 & $86,7 \pm 0,2$ & $-4,9$ & $93,4 \pm 0,6$ & 2,4 & $88,5 \pm 1,3$ & $-3,0$ \\
\hline RC & 132,9 & $134,5 \pm 0,1$ & 1,2 & $134,0 \pm 0,3$ & 0,8 & $134,9 \pm 0,3$ & 1,5 \\
\hline Joelho & 90,6 & $92,1 \pm 0,2$ & 1,7 & $95,1 \pm 0,3$ & 5,0 & $93,8 \pm 0,1$ & 3,5 \\
\hline Pé & 101,8 & $92,9 \pm 0,3$ & $-8,7$ & $100,9 \pm 0,6$ & $-0,9$ & $98,5 \pm 0,8$ & $-3,2$ \\
\hline
\end{tabular}

A maior parte dos valores medidos encontra-se com um desvio menor que $5 \%$ em relação aos valores esperados. Nas medidas com câmara de ionização pode-se observar uma variação maior que a desejada nas medidas do pé. Outro ponto que não se encontra em concordância com os valores esperados foi o ponto de pescoço/nuca. Nesses pontos, aplicam-se vários fatores de correção, sendo que a determinação de dose nos mesmos torna-se menos precisa, pois há uma introdução de pequenos erros em cada fator de correção.

Comparando-se os detectores, a vantagem dos TLDs é que eles são pequenos, não precisam ser conectados a cabos, porém o processo de seleção e calibração é bastante trabalhoso. O microMosfet é pequeno, rápido de calibrar, prático, porém tem necessidade de fios e tempo de vida curto. A câmara de ionização é um dosímetro conhecido de longa data, fornece uma leitura confiável, porém tem a necessidade de cabos, seu tamanho é inadequado para medidas in vivo, além do fato de somente ser possível realizar a medida de um ponto de cada vez. 


\section{CONCLUSÕES}

Analisando os dados obtidos nas medidas de percentual de dose profunda, pode-se observar uma alteração da curva na região próxima da superfície, quando comparadas as medidas com e sem a placa de acrílico. Essa alteração foi satisfatória, uma vez que a região de build up não é desejada para os tratamentos de TBI. Por isso, recomenda-se uso da placa de acrílico.

Em relação às medidas de dose de entrada feitas com o objeto simulador Alderson Rando, é possível concluir que os tratamentos estão de acordo com o planejado. Houve alguns pontos onde o desvio em relação ao valor esperado foi maior que 5\%. Os pontos onde ocorreu esta variação estão localizados nas regiões de maior diferença do diâmetro antero posterior em relação ao ponto de cálculo de dose $(\mathrm{RC})$.

Ainda, o coeficiente de atenuação linear do $\mathrm{Pb}$, medido nas condições de TBI mostrou-se idêntico aquele utilizado nos tratamentos. Para o material cerrobend não foi obtido o mesmo resultado. Porém, como esse coeficiente de atenuação linear tem sido usado desde o início dos tratamentos sem que fosse encontrado nenhum desvio nas medidas in vivo realizadas, o mesmo será mantido provisoriamente e serão realizadas medidas com câmara de ionização em todos os próximos tratamentos até que se esclareça o fato.

Em relação as medida in vivo, recomenda-se o uso de dosímetros em todos os tratamentos de TBI. O dosímetro recomendado é o TLD, pois seu custo é relativamente baixo se comparado aos outros tipos de detectores, sendo que os mesmos podem ser reaproveitados.

Com esse trabalho pode-se concluir que a utilização de instalações convencionais para os tratamentos de irradiação de corpo inteiro é viável desde que sejam feitas as medidas de todos os parâmetros físicos necessários para determinação da dose absorvida nas condições da técnica, validação da dosimetria de TBI e caracterização dos dosímetros a serem empregados na dosimetria in vivo. 


\section{REFERÊNCIAS BIBLIOGRÁFICAS}

AMERICAN ASSOCIATION OF PHYSICS IN MEDICINE (AAPM). The Physical Aspects of Total and Half Body Photon Irradiation. Report 17, 1986.

BUTSON, M.J., CHEUNG, T., YU, P.K.N. Peripheral dose measurement with a MOSFET detector. Applied Radiation and Isotopes, 62, p. 631-634, 2005.

CAMPOS, L.L. Termoluminescência de materiais e sua aplicação em dosimetria da radiação. Scielo Brasil, São Paulo,Nov./Dez, 1998. Disponível em : < http://www.scielo.br/scielo.php?script=sci_arttext\&pid=S0366-

69131998000600007>

Da ROSA, L.A.R. Dosimetria Termoluminescente Aplicada à Física Médica. Instituto de Radioproteção e Dosimetria- IRD, 2000.

INCA. Instituto Nacional do Câncer, Ministério da Saúde, 2006 - 2010. Apresenta informações sobre a incidência de câncer no Brasil. Disponível em < http://www2.inca.gov.br/wps/wcm/connect/agencianoticias/site/home/noticias/2010 /banco_sangue_cordao_umbilical_regiao_norte>. Acesso em 28 ago. 2010.

INTERNATIONAL ATOMIC ENERGY AGENCY. Absorbed Dose Determination in External Beam Radiotherapy. Vienna, 2000. (Technical Reports Series, 398).

IZEWSKA, J., GEORG. D., BERA, P., THWAITES D., ARIB, M., SARAVI, M., SERGIEVA, K., LI, K., YIP, F.G., MAHANT, A.K., BULSKI, W. A methodology for TLD postal dosimetry audit of high-energy radiotherapy photon beams in nonreference conditions. Radiotherapy and Oncology, 84, p. 67-74, 2007.

KAL, H.B., KEMPEN-HARTEVELD, L., HELJENBROK-KAL, M.H., STRULKMANS, $\mathrm{H}$. Biologically Effective Dose in Total-Body Irradiation and Hematopoietic Stem Cell Transplantation. Strahlentherapie und Onkologie. 182, p. 672-679, 2006.

KHAN, F.M. The Physics of Radiation Therapy. Baltimore - William, 1984.

LUO, L.Z. Long term study of Harshaw TLD LiF- LLD and uncertainty. Radiation Measurements. 2009.

MACKINLAY, A.F. Thermoluminescence Dosimetry. Medical Physics Handbook 5, Adam Hilger, Bristol, UK, 1981.

MALICKI, J. The Accuracy of Dose Determination during Total Body Irradiation. Strahlentherapie und Onkologie, 175, p. 208-212, 1999.

McKEEVER, S.W.S.; MOSCOVITCH, M.; TOWNSEND, P.D. Thermoluminescence Dosimetry Materials: Proprieties and Uses. Englang: Nuclear Technology Publishing, 1995.

MEEKS, S.L., PAULINO, A.C., PENNINGTON, E.C., SIMON, J.H., SKWARCHUK, M.W., BUATTI, J.M. In vivo determination of extra-target doses received from serial tomotherapy. Radiotherapy and Oncology, p. 217-222, 2002. 
MERCÊS, N.N.A. Representações sociais sobre o transplante de células tronco hematopoiéticas e do cuidado de enfermagem.2009. Tese (Doutorado) Universidade Federal de Santa Catarina, Santa Catarina.

METCALFE, P.; KRON, T.; HOBAN, P. The Physics of Radiotherapy X-rays from Linear Accelerators. Medical Physics Publishing, Madison, Wisconsin, 1997.

PACYNA, L.G., DARBY, M., PRADO, k. Use of thermoluminescent dosimetry to verify dose compesation in total body irradiation. Medical Dosimetry, Vol 22, p. 319-324, 1997.

PEDERSEN, K., ANDERSEN, T.D., RODAL, J., OLSEN, D.R. Sensitivity and stability of LiF thermoluminescence dosimeters. Medical Dosimetry, Vol. 20, p.263-267, 1995.

PODGORSAK, E.B. Radiation Oncology Physics: A Handbook for Teachers and Students. International Atomic Energy Agency, Vienna, 2005.

RAPLEY, P. Surface dose measurement using tld powder extrapolation. Medical Dosimetry, Vol. 31, p. 209-215, 2006.

Resende G.R.A.; Sales C.P.; Santos G.R.; Gialluisi B.L.; Habtizreuter A.B.; Rodrigues L.N. Avaliação dosimétrica de um detector microMOSFET. Aceito para publicação na Revista Brasileira de Física Médica, 2010.

SOEJIMA, T., HIROTA S., TSUJINO, K., YODEN, E., FUJII, O., ICHIMIYA, Y., MIZUNO, I. Total body irradiation followed by bone marrow transplantation: comparison of once-daily and twice-daily fractionation regimens. Radiation Medicine, 25, p. 402-406, 2007.

WHELDON, T.E., The radiobiological basis of total body irradiation. The British Journal of Radiology, 70, p. 1204-1207, 1997. 